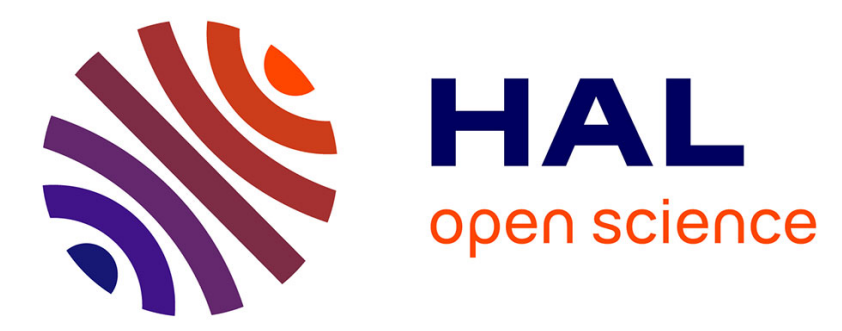

\title{
Assessing the consistency of eddy covariance measurements under conditions of sloping topography within a hilly agricultural catchment
}

Rim Zitouna, Laurent Prevot, Frédéric Jacob, Raoudha Mougou, Marc Voltz

\section{To cite this version:}

Rim Zitouna, Laurent Prevot, Frédéric Jacob, Raoudha Mougou, Marc Voltz. Assessing the consistency of eddy covariance measurements under conditions of sloping topography within a hilly agricultural catchment. Agricultural and Forest Meteorology, 2012, 164, pp.123- 135. 10.1016/j.agrformet.2012.05.010 . hal-02649036

\section{HAL Id: hal-02649036 \\ https: / hal.inrae.fr/hal-02649036}

Submitted on 5 Nov 2021

HAL is a multi-disciplinary open access archive for the deposit and dissemination of scientific research documents, whether they are published or not. The documents may come from teaching and research institutions in France or abroad, or from public or private research centers.
L'archive ouverte pluridisciplinaire HAL, est destinée au dépôt et à la diffusion de documents scientifiques de niveau recherche, publiés ou non, émanant des établissements d'enseignement et de recherche français ou étrangers, des laboratoires publics ou privés.

\section{다)(1) $\$$}

Distributed under a Creative Commons Attribution - NonCommerciall 4.0 International 
1 Assessing the consistency of eddy covariance measurements under conditions of sloping 2 topography within a hilly agricultural catchment.

3

4 Rim Zitouna-Chebbi ${ }^{\mathrm{a},{ }^{*}}$, Laurent Prévot ${ }^{\mathrm{b}}$, Frédéric Jacob ${ }^{\mathrm{c}}$, Raoudha Mougou ${ }^{\mathrm{a}}$, Marc Voltz ${ }^{\mathrm{b}}$ 5

6 a INRGREF, LR GERE, Tunis, Tunisia

7 b INRA, UMR LISAH, Montpellier, France

8 c IRD, UMR LISAH, Montpellier, France

9

10

$11 *$ Corresponding author:

12

13 Rim Zitouna-Chebbi

14 Institut National de Recherches en Génie Rural, Eaux et Forêts

15 Laboratoire de Recherche « Gestion des Risques Environnementaux en Agriculture »

16 Rue Hédy Karray

17 BP 10, Ariana 2080

18 Tunisie

19 Tel: +216-71-709-033

20 Fax: +216-71-717-951

21 rim.zitouna@iresa.agrinet.tn,rimzitouna@live.fr

22

23 
- Eddy covariance (EC) measurements over hillslope under forced convection

- Upward flows: agreement between topography and EC derived airflow inclinations

- Downward flows: differences between topography and EC derived airflow inclinations

- Downward flows: differences ascribed to separation bubble with streamline dilatation

- Energy balance closure similar to reports on flat and mountainous topographies 


\section{ABSTRACT}

The current study addressed the consistency of Eddy Covariance (EC) measurements collected in sloping conditions within a hilly agricultural catchment. In the context of operational monitoring and modelling devoted to decision support, it is important to increase

29 the knowledge of surface fluxes under conditions of hilly topography. The two-metre-high EC 30 measurements were collected at the field scale within the two opposite rims of a V-shaped 31 catchment located in northeastern Tunisia on the southern shore of the Mediterranean Basin. 32 Measurements were collected under bare soil conditions to enhance the effects of the slopes. 33 The data pre-processing and quality control measures were conducted using standard 34 procedures. In assessing the consistency of the EC measurements we first compared the airflow inclinations captured by the EC measurements against the topographical slopes captured by a Digital Elevation Model; we then assessed the energy balance closure. The analysis of the micrometeorological data indicated specific regimes: externally driven winds;

38 forced convection; and stability conditions close to neutrality or low instability. The two dominant wind directions induced upward and downward flows on the two opposite rims. For

40 the upward flows, the airflow inclinations followed the topographical slopes on both fields.

41 For the downward flows, the flows followed the topographical slopes on the southern rim and

42 were almost horizontal on the other rim. In all cases, and especially for the upward flows, the energy balance closure was similar to that reported in the literature. Overall, the behaviour observed for upward flows was close to that reported in the literature for flat conditions, whereas the downward flows exhibited different trends. The different trends we observed for the downward flows were ascribed to the bubble separation zone that implies streamline dilatation, turbulence and reverse flows. Future investigations should address the vegetation conditions. The expected outcomes are of importance for revisiting the operational methods devoted to the estimation of evapotranspiration.

51 KEYWORDS: agricultural hilly catchment, eddy-covariance measurements, sloping conditions, airflow inclination, land surface energy balance. 


\section{INTRODUCTION}

Knowledge of land surface energy fluxes is of paramount importance for water and crop management within semi-arid regions, where the annual actual evapotranspiration amounts to more than two-thirds of the yearly precipitation (Moussa et al., 2007; Daneshkar

59 Arasteh and Tajrishy, 2008). Numerous methods have been developed for measuring and 60 modelling the land surface energy fluxes in flat terrain (Rana and Katerji, 2000; Olioso et al., 61 2002a; Courault et al., 2005). However, little research has been performed for the hilly 62 catchments that correspond to large agricultural areas in many regions of the world (e.g., 63 Mediterranean countries, western Africa, eastern India). Hilly catchments allow water 64 harvesting to be used to secure agricultural production (Mekki et al., 2006; Saha et al., 2007). 65 Our understanding of the energy fluxes and crop evapotranspiration within hilly catchments is still incomplete; a major gap in the knowledge is the influence of the topography on the structure of turbulence within the boundary layer (Raupach and Finnigan, 1997).

Understanding the airflows and surface fluxes over hills was first investigated with wind tunnels (Jackson and Hunt, 1975; Brunet et al., 1994; Poggi and Katul, 2007), and analytical solutions have been proposed for wind and temperature profiles (Jackson and Hunt, 1975; Hunt et al., 1988; Raupach et al., 1992; Kaimal and Finnigan, 1994; Finnigan and Belcher, 2004). However, applying these formulations over hilly catchments is questionable because they are limited to simple two-dimensional hills. Another possibility is the large eddy simulation (LES) technique (Tamura et al., 2007; Dupont et al., 2008). However, LES implementation is a delicate task that requires substantial computer resources, especially over the heterogeneous landscapes that involve large spatial extents and fine spatial resolutions. Furthermore, the application of LES is still limited to simple topography (Dupont et al., 79 2008).

As a result of the aforementioned modelling difficulties and of the increasing availability of eddy covariance (EC) systems, several experimental campaigns have investigated the effects of sloping conditions. These campaigns have involved single flux towers either under mountainous conditions with forests (Geissbühler et al., 2000; Humphreys et al., 2003; Turnipseed et al., 2003) and grasslands (Hammerle et al., 2007; Hiller et al., 
2008), or within hilly catchments with crop systems (Rana et al. 2007; Scott, 2010). Until recently, the experimental costs made it almost impractical to analyse turbulence and advection from the data collected by several nearby EC systems (Feigenwinter et al., 2008).

The effects of slope have been taken into account by applying rotational corrections to the EC measurements, such as the latter fitted to the airflow planes induced by the topographical slopes. When dealing with the single EC towers within hilly agricultural catchments, the energy flux data corrected for slope effects were next used to address the modelling of turbulent exchanges. Thus, Rana et al. (2007) proposed a semi-empirical correction to the turbulent exchange coefficients that accounts for the slope magnitude by extending to non-neutral conditions the neutral wind speed profile relationship proposed by Kaimal and Finnigan (1994). However, follow-up research is needed to extend the few existing works on the EC measurements from single towers; to enable such measurements to be used operationally for monitoring water consumption by crops in hilly catchments, especially in semi-arid regions.

The objective of the current study was to increase the understanding of EC measurements from single towers in sloping conditions within hilly agricultural catchments; by investigating the possible links between the topography, airflow inclinations driven by the wind direction, and surface energy balance closure. We considered a Mediterranean agricultural catchment with hilly topography, locating the EC measurements on the two opposite sides of a valley. We addressed bare soil conditions only, to minimise land-use heterogeneity effects and thus enhance the effects of topography. Section 2 presents the study area, the data collection and processing, including the flux calculation, quality control and footprint analysis, and topographical characterisation from a digital elevation model (DEM). Section 3 reports the analysis of micrometeorological conditions (wind regimes and stability conditions), as well as the results obtained when comparing the airflow inclinations against the topographical slopes and when verifying the energy balance closure according to the airflow inclinations. Section 4 discusses the main outcomes and future directions. 


\section{MATERIALS AND METHODS}

\subsection{Experimental site and calendar}

121
The experiment was set within the agricultural Kamech catchment, which is located in the Cap Bon Peninsula in northeastern Tunisia $\left(36^{\circ} 52^{\prime} 40^{\prime \prime} \mathrm{N}, 10^{\circ} 52^{\prime} 40^{\prime \prime} \mathrm{E}\right.$, Fig. 1). Comprehensive descriptions of the Kamech catchment are given by Mekki et al. (2006) and Raclot and Albergel (2006). This catchment belongs to the long-term environmental research observatory OMERE (a French acronym for the Mediterranean Observatory of Water and the Rural Environment). Within Mediterranean rural catchments, the OMERE studies the impacts of anthropogenic forcing and climate change on hydrology, erosion, and water quality in relation to pollutants (http://www.umr-lisah.fr/omere).

[Figure 1 about here]

The $2.45 \mathrm{~km}^{2}$ Kamech catchment is crossed by the El Gameh wadi from the northeast to the southwest (Fig. 2). The catchment topography is entirely $\mathrm{V}$-shaped from the middle to the south-western parts. The slopes are irregular, especially on the southern rim, which has natural embankments induced by sandstone hogbacks. The altitude ranges between $94 \mathrm{~m}$ and $194 \mathrm{~m}$. The slopes range between $0 \%$ and $30 \%$, the quartiles being $6 \%, 11 \%$ and $18 \%$. Most fields have a small size with an average area of 0.6 ha. The soils have sandy-loam textures, with depths ranging from zero to two metres according to the location within the catchment and the local topography. These swelling soils exhibit shrinkage cracks under dry conditions during the summer (Raclot and Albergel, 2006). The main crops are winter cereals and legumes. The steepest parts of the catchment are used as rangeland for livestock and are therefore covered by natural vegetation. The regional climate is sub-humid with annual values of $600 \mathrm{~mm}$ and $1500 \mathrm{~mm}$ for the precipitation and Penman-Monteith reference crop evapotranspiration, respectively. Because of the combination of sub-humid climate and rainfed agriculture, the catchment is under bare soil conditions from the end of spring to the middle of autumn.

[Figure 2 about here] 
The flux measurements were conducted under bare soil conditions during several months in 2004 and 2006. For both years, a flux station was installed in Field A, located on the northern rim of the catchment (Fig. 2). Field A had an area of 1.1 ha with an homogeneous slope of $5^{\circ}$ facing the south-southeast direction (Fig. 2 and Fig. 3). This field's northern (and upper) limit was close to the rim top, which forms the catchment edge. To collect data on the opposite rim and subsequently to assess the possible effect of slope orientation on energy fluxes, a second flux station was installed in 2006 in Field C, located on the southern rim of the catchment (Fig. 2) and facing northwest. Field C had an area of 2.2 ha and a rugged topography (Fig. 3). The averaged slope around the field centre was approximately $8^{\circ}$. The southern (and upper) limit was close to a plateau, located in the middle of the rim. The northern limit had a natural embankment induced by a sandstone hogback.

[Figure 3 about here] effects, which had an influence on the turbulent fluxes that could be as strong as that of topography (Turnipseed et al., 2003), and (2) a focus on periods during which the land surface conditions were homogeneous throughout the catchment. In 2004, the measurements were collected in Field A from 18 July to 4 November. In 2006, the measurements were collected on fields $\mathrm{A}$ and $\mathrm{C}$ from 20 June to 28 July. The corresponding three data sets were labelled A04, A06 and C06, where the letter represents the field, and the two digits represent the year.

\subsection{Instrumentation and data acquisition}

A meteorological station located near the catchment outlet (labelled $M$ on Fig. 2) measured: (1) the rainfall at a daily time step with a manual raingauge; (2) the solar irradiance with a SP1110 pyranometer (Skye, UK); (3) the air temperature and humidity with an

178 HMP45C probe (Vaisala, Finland); (4) the wind speed with an A100R anemometer (Vector Instruments, UK); and (5) the wind direction with a W200P wind vane (Vector Instruments,

$180 \mathrm{UK}$ ). The instruments were installed $2 \mathrm{~m}$ above ground (except the raingauge, which was set 181 up at $1 \mathrm{~m}$ ) and were connected to a CR10X data-logger (Campbell Scientific, USA). 
182 Variables were samples at $1 \mathrm{~Hz}$ and stored as 30-minute averages. All of the instruments were

183 either new or recently new and had been calibrated by the manufacturer.

The sensible and latent heat fluxes, soil heat flux and net radiation were measured with similar flux stations at fields $\mathrm{A}$ and $\mathrm{C}$. The instruments for each flux station are listed in

187 Table 1. Because the CR23X data-logger has a limited storage capacity, the raw sonic 188 anemometer and krypton hygrometer data were collected at a $10 \mathrm{~Hz}$ frequency and stored on 189 the LoggerNet final storage area \#2 of the CR23X data-logger. These raw data were then 190 downloaded every minute to a laptop through the RS232 serial port. The instruments on Field 191 A in 2004 and on Field C in 2006 were three months old. On field A in 2006, the two-year-old 192 krypton hygrometer did not operate.

The three soil heat flux sensors were distributed two metres away from the station, and were buried between 20 and $50 \mathrm{~mm}$ below the soil surface. The net radiometers were installed $1.5 \mathrm{~m}$ above the ground. The sonic anemometers, the krypton hygrometers, and the air temperature and humidity probes were installed at the same height above the ground during each period of data acquisition: $1.96 \mathrm{~m}$ for Field A in 2004 (data set A04); $1.78 \mathrm{~m}$ for Field A in 2006 (dataset A06); and $2.02 \mathrm{~m}$ for Field C in 2006 (data set C06). The sonic anemometer verticality and the net radiometer horizontality were carefully checked during the experiments with spirit levels, but no realignment needed to be performed. The accuracy of the double spirit level used for the Young sonic anemometer was $0.5 \mathrm{~mm} / \mathrm{m}$, corresponding to an angle of $0.03^{\circ}$. Accuracy on the integrated spirit level of the CSAT sonic anemometer was unknown. Overall, we assumed the accuracy on device alignment was better than $1^{\circ}$. This proposed accuracy was further indirectly confirmed when comparing the flow inclination captured in 2004 and 2006 by the EC device on the same location within Field A. Indeed, the differences between both years were less than $2^{\circ}$ (Section 3.3.2) (Fig. 8a and 8b).

The alternation between the dry and wet periods degraded the krypton hygrometer

$212 \mathrm{KH} 20$. As a result, the KH20 did not operate in 2006 at Field A, and no latent heat flux data 213 were collected for the data set A06. The data acquisition systems were powered by batteries 
214 and solar panels. Because of the high power consumption of the laptop computers, several

215 battery failures occurred, and the $10 \mathrm{~Hz}$ data acquisitions were not continuous. Furthermore,

216 only daytime data were considered for analysis in the context of quantifying

217 evapotranspiration. The daytime periods were defined by the 30 -minute intervals during

218 which the positive values of solar irradiance were measured. After gap removal and daytime

219 observation selection, the numbers of 30-minute intervals with $10 \mathrm{~Hz}$ data acquisition were

220375,463 and 579 for data sets A04, A06 and C06, corresponding to $10 \%, 25 \%$ and $30 \%$ of

221 the experiment durations, respectively.

\subsection{Calculation of net radiation and soil heat flux}

A side-by-side comparison of NR-lite net radiometer measurements was conducted during one month over a natural grass field. This comparison was aimed at ensuring that both the measurements and the subsequent behaviour on the two opposite rims of the $\mathrm{V}$-shaped catchment could be cross-analysed. The comparison of the net radiation data indicated a root mean square difference of $20 \mathrm{~W} \mathrm{~m}^{-2}$ (5\% relative). This difference was notably close to the instrument accuracies. Thus, no correction was applied.

Measurements of net radiation (Rn) were corrected for the effects of slope following the procedure proposed by Holst et al. (2005). Only the direct solar irradiance was corrected

234 by accounting for the angle between the solar direction and the normal to the local 235 topography. The solar direction was derived from time, latitude and longitude with 236 astronomical rules. The local topography was characterised by the slope (topographical zenith 237 with nadir as origin) and aspect (topographical azimuth with north as origin). Both the slope 238 and aspect were calculated using a four-metre spatial resolution DEM obtained by 239 photogrammetry from a stereo pair of panchromatic Ikonos images (Raclot and Albergel, 240 2006). The direct solar irradiance was derived from total solar irradiance measured at the meteorological station (Section 2.2). For this, the diffuse solar irradiance was expressed as an empirical function of atmospheric transmittance; the latter was estimated as the ratio of the

243 solar irradiance measured at the meteorological station to the extra-terrestrial solar irradiance 244 derived from the astronomical rules. The empirical function was calibrated beforehand over 245 the ReSeDA meteorological database that is representative of typical Mediterranean climates 
246 (Olioso et al., 2002b). The obtained calibration was notably close to that proposed by

247 Collares-Pereira and Rabl (1979) and used by Holst et al. (2005).

The average correction of the net radiation measurements for slope effects was approximately $40 \mathrm{~W} \mathrm{~m}^{-2}$ (12\% relative) and $55 \mathrm{~W} \mathrm{~m}^{-2}$ (15\% relative) for fields $\mathrm{A}$ and $\mathrm{C}$, respectively, as indicated by the root mean square differences between corrected and noncorrected data. The maximum corrections reached $60 \mathrm{~W} \mathrm{~m}^{-2}$ for Field $\mathrm{A}$ and $100 \mathrm{~W} \mathrm{~m}^{-2}$ for

253 Field C, and they corresponded to the sunrise or sunset. On average, the corrections induced an increase (respectively decrease) of net radiation measurements on Field A (respectively C). Such between-field differences can be explained by field aspects, because Field A (respectively C) faced the south-southeast (respectively northwest) direction (Section 2.1).

The measurements of soil heat flux (G) are usually corrected for the heat storage 259 between the surface and the sensors (Heusinkveld et al., 2004; Liebethal et al., 2005). 260 However, no correction was performed here because the existing solutions are questionable when considering swelling soils that exhibit shrinkage cracks under dry conditions during the summer (Section 2.1). Neglecting the heat storage induced errors in the soil heat flux measurements of between 20 and $50 \mathrm{~W} \mathrm{~m}^{-2}$ (20\% to $50 \%$ relative), as reviewed by Foken (2008). It was a posteriori verified when analysing the energy balance closure that such errors in soil heat flux were not critical (Section 3.4). Finally, soil heat flux was estimated as the mean value of the measurements collected by the three soil heat sensors distributed around each of the two stations.

\subsection{Calculation of the EC-based convective fluxes and airflow inclinations}

The three convective fluxes (friction velocity $\mathrm{u}_{*}$, sensible heat flux $\mathrm{H}$ and latent heat

272 flux $\lambda \mathrm{E}$ ) and the angles for characterising the airflow inclinations were calculated from the $27310 \mathrm{~Hz}$ data collected with the sonic anemometer and the krypton hygrometer with the 274 ECPACK library version 2.5.22 (http://www.met.wau.nl/projects/jep/report/ecromp/, van Dijk 275 et al., 2004). We present hereafter the different steps of the calculations. We note $\mathrm{u}_{*}$ was used for both controlling the data quality and calculating the EC data footprint. 
The entire set of instrument corrections proposed in the aforementioned version of the ECPACK library was applied. These corrections addressed the following items: (1) the calibration drift of the krypton hygrometer with the air humidity and temperature measured by the HMP45C probe over each 30-minute interval; (2) the linear trends over the 30-minute intervals; (3) the sonic anemometer temperature for humidity; (4) the hygrometer response for oxygen sensitivity; (5) the mean vertical velocity (Webb term); and (6) the correction for the frequency response (spectral loss) and path averaging. In relation to a low measurement height of approximately $2 \mathrm{~m}$ above surface level (Section 2.2), the correction for the frequency response increased the flux magnitudes by $0.01 \mathrm{~m} \mathrm{~s}^{-1}(2 \%$ relative $), 10 \mathrm{~W} \mathrm{~m}^{-2}(5 \%$ relative) and $5 \mathrm{~W} \mathrm{~m}^{-2}\left(8 \%\right.$ relative) for $\mathrm{u}_{*}, \mathrm{H}$ and $\lambda \mathrm{E}$, respectively. The resulting convective fluxes were labelled NR for Non-Rotated.

A side-by-side comparison of the EC device measurements was conducted during one month within Field A. This comparison aimed at ensuring it was possible to compare the measurements and subsequent behaviour on the two opposite rims of the V-shaped catchment.

295 The comparison of convective flux data indicated a root mean square difference of $20 \mathrm{~W} \mathrm{~m}^{-2}$ 296 (15\% relative). This difference was close to the accuracy of the EC data, which are widely accepted to be between 20 and $50 \mathrm{~W} \mathrm{~m}^{-2}$ for the latent heat and between 10 and $30 \mathrm{~W} \mathrm{~m}^{-2}$ for the sensible heat flux, which corresponds to 5-20\% relative (Foken, 2008). Thus, no correction was applied.

\subsubsection{Rotational corrections and airflow inclination}

The sonic anemometers were installed vertically, although the sloping conditions were suspected to induce non-horizontal airflows. The rotational corrections were applied to correct the fluxes for the airflow inclination, as explained hereafter.

The three-dimensional sonic anemometers measure wind speed in three perpendicular 308 directions (labelled $\mathrm{u}$ and $\mathrm{v}$ in the horizontal plane and $\mathrm{w}$ in the vertical). When estimating the convective fluxes from the EC measurements, the rotations are usually applied to the 
coordinate system (Kaimal and Finnigan, 1994). Over flat terrain, the aim is to account for the incorrect vertical alignment of the sonic anemometer. Over slopes, the aim is to virtually align the sonic anemometer perpendicularly to the airflow streamlines (Geissbühler et al., 2000; Humphreys et al., 2003; Lewicki et al., 2008). These rotations are usually defined by three angles: the yaw angle, which is a rotation around the vertical axis that aligns $u$ with the wind direction; the pitch angle, which is a rotation around the horizontal axis perpendicular to the wind direction that sets $\mathrm{w}$ to zero; and the roll angle, which is a rotation around the horizontal axis parallel to the wind direction.

Amongst the existing possibilities for performing rotational corrections, we selected the planar fit correction introduced by Wilczak et al. (2001) and implemented in the ECPACK library. This method has been recommended by several authors (Massman and Lee, 2002; Turnipseed et al., 2003; Lee et al., 2004) for correcting EC measurements acquired over sloping terrain. Assuming the airflow streamlines are included in a plane, the latter is fitted to a set of wind speed components collected over a long time interval, typically ranging from one to several days. Thus, the planar fit correction is less sensitive to the sampling errors than the double and triple rotation corrections (Turnipseed et al., 2003), where the latter are applied to each integration interval (30 minutes in our case). Because the current study focused on the daytime data, the planar fit correction did not suffer from uncertainties resulting from low night-time wind speeds.

Over heterogeneous terrain that induces anisotropic airflow, the tilt angles (pitch and roll) are likely to depend upon the wind direction (yaw angle). Consequently, the airflow inclination for various wind directions cannot be adequately represented by a single plane only. The $10-\mathrm{Hz}$ EC data were therefore grouped according to wind direction (or wind sectors). Two calculations were made to ensure that the planar fit angles were not sensitive to the time interval over which they were estimated. A single plane was fitted over all of the data belonging to a wind sector for a given data set (A04, A06, and C06). Additionally, for a given field (A or C), one plane was fitted for each wind sector and each day. We a posteriori verified that considering these two methods provided similar results for airflow inclination, as captured with planar fit angles (Section 3.3) and flux magnitude (Section 3.4). 
The planar fit provided the inclination angles of the plane that fitted the wind speed

343 components over a given time interval in which the angles are in a coordinate system fixed to

344 the anemometer. For a given plane inclination provided by the planar fit angles, along with

345 the anemometer orientation that had previously been determined when setting up each flux

346 station, it was possible to calculate the airflow inclination for any wind direction, including

347 those that corresponded to the yaw angle measurements.

Finally, the planar fit angles calculated at the daily timescale for each wind sector were

350 introduced into the planar fit correction of the fluxes, and the resulting convective fluxes calculated over 30-minute intervals were labelled PF (Planar Fit).

\subsubsection{Quality control}

The quality control of the 30-minute flux data was performed using two standard tests that are routinely employed over sloping terrains. These tests ensure that the theoretical requirements for the EC measurements are fulfilled (Geissbühler et al., 2000; Rebmann et al., 2005; Hammerle et al., 2007, Hiller et al., 2008).

The steady-state (ST) test (Foken and Wichura, 1996) characterises the turbulence time homogeneity for the three convective fluxes. This test compares the average flux values over each 30-minute interval with the averaged values over the six corresponding 5-minute subintervals. The integral turbulence characteristics (ITC) test (Foken and Wichura, 1996;

364 Rebmann et al., 2005) characterises the development of turbulence and therefore the spatial homogeneity in terms of the surface aerodynamic properties. For that characterisation, the test compares the measured flux-variance similarities to those obtained from the empirical models based on Monin-Obukhov similarity theory. Over each 30-minute interval, the flux-variance similarities are tested for the horizontal wind speed $\mathrm{u}$, vertical wind speed $\mathrm{w}$ and air 369 temperature $\mathrm{T}$.

Both the ST and the ITC tests are expressed as absolute values of the relative 372 differences. These tests allow the data to be ranked (Foken et al., 2004; Rebmann et al., 373 2005): the high-quality turbulence data (test values less than 0.3 ); good quality data for the 
374 flux measurements (test values between 0.3 and 1.0); and low-quality data (test values greater 375 than 1.0).

2.4.4 Footprint of the EC fluxes

Quantifying the area that contributed to each flux measurement - the so-called 380 footprint area - was an important step for characterising the representativeness of the measured fluxes. This step was also important for analysing any topographical influence on the flux measurements because this analysis required the knowledge of the relief within the contributing areas.

The footprint of each 30-minute sample of the EC flux data was estimated using the approach of Horst and Weil (1994), which relies on an analytical dispersion model that accounts for the effects of atmospheric stability. The Horst and Weil model offered a good compromise between ease of implementation and estimate reliability. Furthermore, the assumption of the spatial uniformity and temporal constancy of the surface roughness in the Horst and Weil model was well-fulfilled during the experiment because (1) each field and all surrounding plots were bare soil only, and (2) the flux data were filtered using the ST and ITC tests (see Section 2.4.3). For each flux estimate derived from the EC data via the ECPACK library, the footprint area was calculated from the outputs of the Horst and Weil model as the ellipsoid from which $90 \%$ of the flux originated. Each footprint ellipsoid was characterised by its length (respectively width) along (respectively across) the wind direction. The footprint ellipsoids were then combined with the digital map of the field boundaries (Fig. 3) to quantify the proportion of the measured fluxes that originated from the field on which the flux station was installed (field A or C).

\subsection{Evaluation of the topographical slopes for the flux measurements}

To understand the effects of relief on the energy fluxes, the topography near each flux 
406 direction fluctuated on a scale of 10 to 30 minutes, the terrain slopes for the dominant wind

407 directions needed to be evaluated within these time intervals. Thus, we calculated the terrain 408 slopes for all wind directions. The procedure was twofold.

First, we defined a rectangle centred on the flux station and oriented along a given 411 wind direction (yaw angle). The rectangle width was set to twice the median value of the

412 footprint width (the ellipsoid width across the wind direction, Section 2.4.4) and its length 413 was set to twice the median value of the footprint length (ellipsoid length along wind 414 direction, Section 2.4.4). We considered the median values of the footprint dimension twice to 415 account for the influence of the upstream / downstream relief on the flow structure. Once each 416 rectangle was defined, we extracted the corresponding altitude data from the DEM 417 (Section 2.3), and a topographical plane was fitted against the DEM data (i.e., the altitude 418 versus northing and easting coordinates). The topographical plane equation was next used to 419 calculate two terrain slopes geometrically similar to the angles given by the rotational 420 correction (Section 2.4.2): the along-wind slope corresponded to the pitch angle, and the across-wind slope corresponded to the roll angle.

The above approach was chosen for three reasons: (1) it defined a wind-oriented topography (along and across slopes); (2) these slopes were evaluated in a similar way to the rotational correction characterising the airflow inclination; and (3) it accounted for the spatial extent of the footprint area. The choice of a rectangle instead of an ellipsoid simplified the 427 calculations.

\section{RESULTS}

In this section we first analysed the meteorological data to characterise the 432 micrometeorological conditions, including the wind and convection regimes (Section 3.1). 433 Secondly, we analysed the results of the flux data quality control and the footprint estimates 434 (Section 3.2). Thirdly, we characterised the DEM-derived topographical slopes according to 435 the wind direction and then compared them against the airflow inclinations derived from the rotational corrections of the EC data (Section 3.3). We finally addressed energy balance 
437 closure (Section 3.4). These analyses were conducted by comparing the results obtained on

438 the two opposite rims of the catchment (e.g., over fields A and C).

\subsection{Climatic conditions}

\subsubsection{Wind regime}

The data from the meteorological station showed large wind speed values with a mean

445 daytime value of $4 \mathrm{~m} \mathrm{~s}^{-1}$ that was twice as large as the FAO mean value for more than 2000 446 sites around the world (Allen et al., 1998). These wind speed measurements closely agreed

447 with those collected by the sonic anemometers within fields $\mathrm{A}$ and $\mathrm{C}$ - the differences were 448 less than $1 \mathrm{~m} \mathrm{~s}^{-1}$. This wind speed homogeneity was observed in previous studies conducted at 449 different locations within the Kamech catchment (Zitouna-Chebbi, 2009).

Fig. 4 presents the wind roses obtained from the data collected at the meteorological 452 station. These wind roses clearly show the existence of two dominant directions: winds coming either from the northwest or from the south (actually south-southeast). This bi-modal 454 regime of northwest and south winds was observed throughout the experiment (years 2004 and 2006). At the daily timescale, no diurnal cycle was observed for the wind direction.

[Figure 4 about here]

To seek possible influences of wind direction on the turbulent fluxes, we distinguished

460 two dominant wind direction classes according to the observations displayed in Fig. 4 461 (clockwise degrees, north is $0^{\circ}$ ): winds coming from directions between the southwest $\left(220^{\circ}\right)$ 462 and east-northeast $\left(70^{\circ}\right)$, known hereafter as the northwest winds; and winds coming from the 463 other directions, known hereafter as south winds. For both 2004 and 2006, the proportions of 464 the northwest and south winds were $70 \%$ and $30 \%$, respectively. These two dominant 465 directions were almost perpendicular to the valley axis (Fig. 2). Therefore, the northwest 466 winds induced simultaneous downward flows on the northern rim (Field A) and upward flows on the southern rim (Field C). The reverse was observed with the south winds. 
3.1.2 Micrometeorological conditions

470

471

472

473

474

475 day).

\subsubsection{Quality control of the EC data} experiments.

As is typical for summer in the study site, rainfall amounts were notably low during the experiments with a total amount of $1.5 \mathrm{~mm}$ for the data sets A06 and C06. A larger value $(81 \mathrm{~mm})$ was observed for data set A04 because the experiment lasted until the beginning of autumn (Section 2.1). The reference evapotranspiration $\left(\mathrm{ET}_{0}\right)$ was calculated from the data collected at the meteorological station by following Allen et al. (1998). For the data set A04 (respectively A06 and C06), the $\mathrm{ET}_{0}$ ranged between 1.4 and $10.4 \mathrm{~mm}$ per day (respectively 4.7 and $10.3 \mathrm{~mm}$ per day), with a mean value of $4.6 \mathrm{~mm}$ per day (respectively $6.6 \mathrm{~mm}$ per

As expected for the day-time measurements under windy conditions (Section 3.1.1), the Monin-Obukhov stability parameter (MOSP) was always negative, with notably few values less than -0.1 . For the northwest (respectively south) winds, the MOSP median values were $-0.042,-0.053$ and -0.057 (respectively $-0.059,-0.022$ and -0.022 ) for the datasets A04, A06 and C06. These values corresponded to the conditions of neutrality or low instability.

\subsection{Quality control and footprints of the EC data}

The results of the quality control test in Table 2 are given for the EC flux data after the rotational correction. On average, $90 \%$ of the $\mathrm{u}_{*}$ and $\mathrm{H}$ fluxes reached the first quality class for both the ST and ITC tests. For the latent heat flux, 70\% of the data reached the first quality class. The good results obtained with the ST test a posteriori justified the integration of the EC data over the 30-minute intervals. The good results obtained with the ITC test showed that the surface aerodynamic properties were spatially homogeneous near the flux stations, which was in agreement with the bare soil conditions observed throughout the catchment during the 
The current study addressed the energy fluxes under sloping conditions within a hilly

502 catchment in the context of operationally monitoring crop water consumption under a semi503 arid climate. Thus, only the data belonging to the first two quality classes (ST and ITC test 504 values less than 1.0) were selected for further investigation. This represented $99 \%$ of the $u_{*}$ 505 and $\mathrm{H}$ fluxes and $76 \%$ of the $\lambda \mathrm{E}$ fluxes. Finally, we note applying rotational corrections 506 induced larger amounts of data fitting the quality control test, where the number of rotated 507 data in the first two quality classes increased by $40 \%$ relative to the number of non-rotated 508 data.

\subsubsection{Footprints of the EC fluxes}

The footprint areas were calculated using the EC flux data after the rotational correction. For each 30-minute interval, the calculated footprint areas were superimposed on

514 the field map (Fig. 3), which allowed an evaluation of the percentage of fluxes originating 515 from the considered field. On average and regardless of wind direction, 55\% (respectively 516 60\%) of the flux measurements originated from Field A in 2004 (respectively 2006) and 80\% 517 originated from Field $\mathrm{C}$ in 2006. Although these fields were selected as the best locations 518 within the catchment, these contributions were found to be moderate. However, this result was not considered to be a critical issue because the surface conditions of the surrounding fields were similar (bare soils), which was confirmed by the good results obtained with the ITC test (Section 3.2.1).

The mono-modal distributions of the lengths and widths of the ellipsoid-shaped 524 footprints are given in Fig. 5. The median values of the footprint lengths were $208 \mathrm{~m}, 180 \mathrm{~m}$ and $182 \mathrm{~m}$ for the A04, A06 and C06 data sets, respectively. The median values of the widths were $62 \mathrm{~m}, 58 \mathrm{~m}$ and $58 \mathrm{~m}$ for the A04, A06 and C06 data sets, respectively. No significant influence from the wind directions (northwest and south) was observed for the footprint dimensions, with the differences between median lengths being less than $15 \%$ relative. This was expected because the micrometeorological conditions did not significantly vary with the

530 wind direction. 


\section{$534 \quad 3.3$ Influence of the topography on the airflow inclination}

3.3.1 Determination of the terrain slopes from DEM data

According to the results from Section 3.2.2, the length of the rectangles used to

539 determine the terrain slopes from the DEM-based altitude data was fixed at $360 \mathrm{~m}$, which is

540 twice the median value of the ellipsoid footprint lengths. The width of these rectangles was

541 fixed to $120 \mathrm{~m}$, which was twice the median of the ellipsoid footprint widths.

The fitting of the terrain slopes for the south winds (yaw angle $=180^{\circ}$ from north clockwise) and the northwest winds (yaw angle $=320^{\circ}$ from north clockwise) are illustrated in Fig. 6, where the slanted thick lines represent the pitch angle calculated over the $360-\mathrm{m}$ long and 120-m wide rectangles (Section 2.5).

In the vicinity of Field A, the topography at the 360-m scale appeared to be almost planar for both the south and northwest winds. The top of the northern rim, which corresponded to the catchment northwest limit (see Fig. 2), formed a sharp hill that is clearly visible on Fig. 6 for the south winds (right vertical arrow at $\mathrm{x}=290 \mathrm{~m}$ on top left subplot) and for the northwest winds (left vertical arrow at $\mathrm{x}=-270 \mathrm{~m}$ on top right subplot). Field $\mathrm{C}$ had a rugged relief with more dispersion of the altitude data and a less planar shape, especially for the south winds. The hilltop at the field southern limit $(x=-300$ to $-200 \mathrm{~m}$ on the bottom left subplot, $x=150 \mathrm{~m}$ on the bottom right subplot) was rugged compared to the top of the northern rim. The catchment southern limit was located $700 \mathrm{~m}$ south from Field $\mathrm{C}$ (left vertical arrow on bottom left subplot, and right vertical arrow on bottom right subplot).

562 were allocated to the downward (respectively upward) flows. Fig. 7 displays the evolution of 563 the topographical pitch terrain slope and roll terrain slope with respect to the yaw angle. On 564 Field A, the pitch and roll terrain slopes ranged from 0 to $5.2^{\circ}$ in absolute value, whereas they 
ranged from 0 to $8.5^{\circ}$ in absolute value on Field $\mathrm{C}$, indicating a larger slope. As expected, the pitch and roll terrain slopes were in phase quadrature for both fields. For a given field, we observed different shapes for the pitch and roll curves. This finding was explained by the use of a rectangle when extracting the DEM data to calculate the terrain slopes (Section 2.5 and 3.2.2), where the pitch angle corresponded to the rectangle length, whereas the roll angle corresponded to the rectangle width. The quasi-sinusoidal shape observed for both the pitch and roll terrain slopes on Field A confirmed its almost planar shape, whereas the more complex evolution of the roll terrain slope on Field $\mathrm{C}$ corresponded to its rugged relief, as already observed in Fig. 6.

\section{[Figure 7 about here]}

\subsubsection{Comparison of the EC-based flow inclination against the DEM-based terrain slopes}

The planar fit angle calculation for a given data set (A04, A06 and C06) was twofold, either fitting a single plane over all of the data belonging to a wind sector (northwest or south) or fitting a plane for each wind sector and each day (Section 2.4.2). The first calculation yielded two planes corresponding to the northwest and south sectors for each data set. When fitting a plane for each wind sector and each day, this calculation yielded between seven and 23 daily planes in accordance with the number of 30 -minute intervals of $10-\mathrm{Hz}$ data collected (Section 2.2).

Fig. $8 \mathrm{a}$ and $8 \mathrm{~b}$ display the evolution of the pitch and roll angles according to the yaw angle when comparing the estimates from the DEM data and from the planar fit rotational correction of the EC data. The continuous lines correspond to the DEM-derived topographical slopes (Section 3.3.1). The discontinuous (dashed or dotted in accordance with year) lines correspond to the planar fit derived slopes when considering a unique plane fitted over all data belonging to a wind sector (northwest or south) for a given data set. In this case, pitch and roll angles are calculated from the fitting plane by setting a $1^{\circ}$ step range of the yaw angle values that spread over the corresponding wind sector. The points are related to the planar fit-derived slopes when considering each wind sector and each day. 
[Figure 8a about here]

For each data set (A04, A06, C06) and each wind sector (northwest, south) the planar

602 fit estimates of pitch angles at the daily scale (symbols) were in close agreement with those

603 calculated over the entire data sets (portions of broken curves). This result was explained by

604 the bare soil conditions during the experiments, inducing little or no variation of the surface

605 roughness. Thus, the daily evaluation of the planar fit-derived pitch angles appeared to be 606 stable. For the planar fit-derived roll angles, a lower but correct agreement was observed between daily estimates and the averaged values over the experiment.

For the upward flows (positive values of the pitch angles), Fig. 8a shows an excellent 610 agreement between the pitch slope estimates from the planar fit correction and from the DEM 611 data. This agreement indicated that the airflow inclination, as captured by the planar fit 612 correction, followed the along-wind topographical slope deduced from the DEM data. As 613 indicated by the discontinuous lines, the differences between 2004 and 2006 for Field A were 614 within $1.5^{\circ}$. For the downward flows (negative values of the pitch angles), the agreement was 615 also excellent on Field C. A different behaviour was observed on Field A, where the planar 616 fit-derived pitch angles were close to nil, varying between $-2.5^{\circ}$ and $+1^{\circ}$ in 2004 and between $617-1^{\circ}$ and $0^{\circ}$ in 2006 . The inclination flow, as captured by the planar fit correction of the EC 618 data, thus appeared to be almost horizontal.

Notably similar findings were found when comparing the roll angles deduced from the 621 planar fit correction to those calculated from the DEM data, as observed on Fig. 8b. On Field $622 \mathrm{C}$, the planar fit roll angles were in close agreement with the topography (within $2^{\circ}$ ) for all of 623 the wind directions and for a large range of topographic slopes $\left( \pm 7^{\circ}\right)$. On Field $A$, the planar 624 fit roll angles were in good agreement with the topography (within $3^{\circ}$ ) under the upward 625 flows and were close to nil (between $-2^{\circ}$ and $+3.6^{\circ}$ ) under the downward flows. The 626 difference between the planar fit roll angles obtained in 2004 and 2006 remained less than $3^{\circ}$. 
Summarising the observations reported above: for the upward flows, the airflow pitch

629 (respectively roll) angles, as captured by the planar fit correction of the EC data, were in close

630 agreement with the topographical slope along (respectively across) the wind direction. For the downward flows, the airflow pitch and roll angles were in close agreement with the topographical slopes on Field C, whereas they tended toward being horizontal on Field A.

\subsection{Energy balance closure}

We analysed the energy balance closure by comparing the sum of convective energy $(\mathrm{H}+\lambda \mathrm{E})$ against the available energy $(\mathrm{Rn}-\mathrm{G})$. The convective fluxes were those obtained from the EC flux data after the rotational correction. Although the usefulness of such analysis as a quality test may be debatable (Lee et al., 2004), it was considered an interesting comparison of the independent measurements. The data to be compared were those calculated over the 30 minute intervals (Section 2.2 and 2.4.2).

Given that no latent heat flux data were collected for the data set A06 because of the krypton hygrometer inoperability, the energy balance closure could be analysed only for the data sets A04 and C06. This issue was not critical because the previous observations noted for the A06 data set were nearly identical to those noted for the A04 data set, when comparing the planar fit angles against the terrain slopes (3.4.2). Next, the number of data involved in the energy balance closure analysis resulted from several filters. First, the convective flux data were filtered with quality control (Section 3.2.1). Second, an additional filter consisted of removing the data that corresponded to the negative values for the available energy. Finally, the number of available observations for assessing the energy balance closure was constrained by the smallest data set among the net radiation, soil heat flux, sensible and latent heat flux.

The energy balance closure is graphically presented in Fig. 9, and the corresponding 655 statistics are given in Table 3. The energy balance closure, as expressed through the energy 656 balance ratio, ranged between 87 and 95\%, with the exception of one case (the downward flows on Field C in 2006) that corresponds to 73\%. Regardless of the considered case (A04 and C06 data set, the upward and downward flows), the energy balance closure was comparable to those found in the literature under various conditions, such as vegetated 
660

canopies and bare soils under flat and mountainous conditions (Wilson et al., 2002; Hammerle et al., 2007; Foken, 2008). We also observed from our data set that the available energy systematically overestimated (respectively underestimated) the convective energy for large (respectively low) values, which was also in agreement with the aforementioned literature.

[Figure 9 about here]

[Table 3 about here]

The $20-50 \mathrm{~W} \mathrm{~m}^{-2}$ error for the soil heat flux that resulted from neglecting the heat storage between the surface and plates (Section 2.3) was not considered to be a critical issue. Indeed, the resulting error had the same magnitude as the measurement uncertainty resulting from the instrumental errors and spatial variability (Stannard et al., 1994; Kustas et al., 2000; Olioso et al., 2002b; Shao et al., 2008). Most importantly, the energy balance closure reported in this study was similar to those reported in previous studies that accounted for the heat storage when measuring the soil heat flux (Wilson et al., 2002; Hammerle et al., 2007; Foken, 2008).

When analysing the energy balance closure as a function of the upward and downward flows, the results for the energy balance closure were similar on Field A, but they were better for the upward flow compared to the downward flow on Field C. On Field A, the systematic errors were similar for the upward and downward flows with similar slope and offset values for the linear regression of the convective energy against the available energy. The random error was smaller for the upward flows (unsystematic root mean square error of $39.6 \mathrm{~W} \mathrm{~m}^{-2}$ versus $47.4 \mathrm{~W} \mathrm{~m}^{-2}$ ), but the energy balance residual (difference between available and convective energy) was smaller for the downward flows $\left(12.2 \mathrm{~W} \mathrm{~m}^{-2}\right.$ versus $\left.32.7 \mathrm{~W} \mathrm{~m}^{-2}\right)$. On Field $\mathrm{C}$, the random error was larger for the upward flows (unsystematic root mean square error of $34.9 \mathrm{~W} \mathrm{~m}^{-2}$ versus $25.6 \mathrm{~W} \mathrm{~m}^{-2}$ ), but the systematic error and the energy balance residual were larger for downward flows (slope value of 0.64 versus 0.73 ; energy balance residual of $81.2 \mathrm{~W} \mathrm{~m}^{-2}$ versus $26.9 \mathrm{~W} \mathrm{~m}^{-2}$ ). The most important result for Field $\mathrm{C}$ was the magnitude of the energy imbalance for the downward flows, approximately $27 \%$, compared to the other values, which ranged between $5 \%$ and $13 \%$. 
We finally analysed the impact of the rotational corrections on the energy balance 694 closure to compare with previously published results. We expected our findings to increase 695 our confidence in the EC measurements performed under the conditions of hilly topography. 696 The planar fit correction increased the convective fluxes for the upward flows (between 5 and $69750 \mathrm{~W} \mathrm{~m}^{-2}$ depending on the field, year and convective flux), whereas it decreased the 698 convective fluxes for the downward flows, especially on Field $\mathrm{C}$ (by as much as $90 \mathrm{~W} \mathrm{~m}^{-2}$ ).

699 As expected, the magnitude of the planar fit correction was linked with the magnitude of the 700 airflow inclination. Indeed, the horizontal airflows for the downward flows on Field A corresponded to the negligible planar fit correction for the convective fluxes. Furthermore, the planar fit correction was similar for the flux magnitude when comparing the two methods that we considered for calculating planar fit angles (Section 2.4.2), with differences of less than $10 \mathrm{~W} \mathrm{~m}^{-2}$ being observed. Finally, the energy balance closure was systematically improved after the planar fit correction (increase of EBR ratio values from 0.8 to 0.92 on average) apart from the downward flows on Field C.

\section{DISCUSSION}

For the wind regime, we had notably different findings when addressing the sloping 711 effects within the Kamech hilly agricultural catchment compared to the previous studies that 712 addressed slope effects within mountainous areas (Hammerle et al., 2007; Hiller et al., 2008).

713 We did not observe the diurnal cycle of wind direction, anabatic and katabatic winds that blew up and down the slopes or the valley winds that followed the longitudinal axis of the catchment. This finding suggested the wind regime was externally driven and did not depend upon the local topography. We observed large wind speed values, which may be explained by

717 the location of the catchment near the extremity of the Cap Bon Peninsula. The large wind 718 speed values were in agreement with the micrometeorological data that indicated the 719 dominant regimes of forced convection along with the conditions of near-neutrality or low 720 instability.

When comparing the inclination flow derived from the planar fit correction of the EC measurements against the topographical slopes derived from the DEM data, different 
724 situations were observed. For the upward flows, the planar fit angles were in notably good

725 agreement with the topographical slopes, which indicated that the airflow followed the terrain 726 slope along the wind direction. This result was observed on both fields $\mathrm{A}$ and $\mathrm{C}$ with the 727 different EC devices (Section 2.2) and on Field A for two different years (2004 and 2006).

728 For the downward flows, the planar fit angles were either in good agreement with the 729 topographical slope for Field C or were close to nil for Field A.

The differences we observed between the upward and downward flows were not ascribed to the differences in the meteorological or micrometeorological conditions. Because the EC data were collected over two opposite sides of the watershed, the upward flows on a given side correspond to the downward flows on the opposite side for the same meteorological conditions and wind direction.

The verticality of the EC devices could not be set and controlled numerically. Nevertheless, the resulting inaccuracy of the alignment of the EC devices could not weaken the findings on the change in flow inclination according to the upward and downward flows.

740 First, the same behaviour was observed in Field A in 2004 and 2006, where the agreement between the flow inclination and topographical slope was good despite small differences in the flow inclination between 2004 and 2006 (Fig. 8a and 8b). Second, the error of the alignment for each EC device did not affect the relative difference between the flow inclination for the upward and downward flows; this difference remained unchanged regardless of the EC alignment.

When comparing the airflow inclinations against the topographical slopes for the 748 downward flows, the abovementioned differences between fields $\mathrm{A}$ and $\mathrm{C}$ were ascribed to 749 the topographical conditions. The hillslope geometries were different because Field A 750 depicted a twofold-lower ratio of the altitude difference to the length (0.1 versus 0.2) (Fig. 6), 751 where this ratio is similar to the ratio of height to the half-length commonly used to 752 characterise the flows over hills (Raupach and Finnigan 1997, Finnigan and Belcher 2004). 753 These differences in the hillslope geometries were combined with differences in the locations 754 of the EC flux stations within the hillslopes, closer to the rim top than to the valley bottom on 755 Field A (top right subplot of Fig. 6 for northwest winds) and conversely for Field C (bottom 
left subplot of Fig. 6 for south winds). Thus, the EC flux stations had different locations within the separation bubble that is characterised by the airflow variability (Raupach and Finnigan 1997, Belcher et al., 2008). Furthermore, asymmetry between the upward and downward flows, as observed on Field A but not on Field C, was also reported by Finnigan and Belcher (2004). However, a comparison with the outcomes from such modelling studies should be substantiated. First, these modelling studies addressed the downward flows within the lee of the hill without any obstacle from the downstream topography. Second, the downward flows that we addressed in this study were in equilibrium with the downstream topography induced by the opposite rim of the catchment.

Apart from the downward flows of Field C, the energy balance closure was similar in all of the cases and improved after the application of the planar fit correction. Both findings were similar to those reported in the literature (Wilson et al., 2002, Hammerle et al., 2007; Foken, 2008). The available energy tended to overestimate the convective energy, as reported by Foken (2008). The worse results for Field C may be explained by the location of the EC flux station on the hillslope. Indeed, Finnigan (2004) suggested the location of the flux station relative to the hilltop is critical for flux accuracy, which depends upon the wind direction.

Overall, applying the rotational correction improved both the data filtering and the energy balance closure. This result was in agreement with the outcomes from other studies that mainly focused on flat or mountainous conditions. Such agreement was considered as an indicator of the data consistency and reliability. This is an important outcome for the data collected under these specific conditions that has been barely addressed until now (i.e., hilly topography).

Analysis of the results was conducted by differentiating the upward and downward flows. According to this analysis, the upward flows appeared to induce behaviours similar to those observed under flat conditions. Indeed, streamlines followed the local topography, whereas the energy balance was improved after the planar fit correction that increased the fluxes. Different behaviour was observed for the downward flows, possibly induced by the streamline dilatation and reverse circulation flow (Raupach and Finnigan 1997; Belcher et al., 2008). Furthermore, the results were worse for Field C, which may be explained by the 
complex topography of the southern rim. First, the rugged topography may induce complex turbulence structures; second, the rugged topography induced differences in the solar heating for bare soils, which may result in horizontal advection.

\section{CONCLUDING REMARKS}

Hilly catchments are widespread throughout the world. In arid and semi-arid climates, they have socioeconomic implications with regard to water harvesting for agricultural production. Our understanding of surface fluxes within such areas must be improved in the context of operational monitoring and modelling for decision-support purposes. The current paper offered insights regarding energy fluxes from a hilly catchment under bare soil conditions, but further research is needed. Beyond the previous studies that addressed sloping terrain vegetated with tall canopies (e.g., forests); the fluxes over agricultural canopies must also be investigated. Indeed, vegetation is known to affect the pressure gradient associated with the flow over hills (Finnigan and Brunet, 1995, Finnigan and Belcher, 2004) and thus to influence the airflow and surface fluxes (Raupach and Finnigan, 1997; Turnipseed et al., 2003). Furthermore, these vegetation effects may combine with the topography and wind direction. Finally, the aerodynamic implications must be emphasised, where the roughness length should be revisited relative to the asymmetry between the upward and downward airflows, as suggested by Finnigan and Belcher (2004). This approach will enable the expansion of the recent modelling works (Rana et al., 2007) with implications for the operational FAO-56 method (Allen et al., 1998).

\section{Acknowledgments}

Financial support for this study was provided by (1) the French Institute of Research for Development (IRD) through the Department for Support and Training and through the Environmental Research Observatory OMERE; (2) the European Union (Seventh Framework Programme) through the IRRIMED project (contract ICA3-2002-10080); and (3) the Agropolis Foundation (Thematic Network of Advanced Research "Montpellier Agronomy and Sustainable Development") through the "Land surface atmosphere exchanges within hilly watersheds" project (contract 0901-013). The authors wish to thank Henk de Bruin and Oscar 
820 Hartogensis for their technical support in processing the EC data. We give warm thanks to

821 Yves Brunet for the constructive criticism of the manuscript and for the subsequent 822 discussions. We are also grateful to John Gash for manuscript edition. This paper is dedicated 823 to the memory of Raoudha Mougou.

\section{References}

826

827 Allen, R.G., Pereira, L.S., Raes, D., Smith, M., 1998. Crop evapotranspiration: guidelines for 828 computing crop water requirements. FAO Irrigation and Drainage Paper No. 56, FAO, Rome, 829 300pp.

831 Belcher, S.E., Finnigan, J.J., Harman, I.N., 2008. Flows through forest canopies in complex 832 terrain. Ecol. Appl. 18 (6), 1436-1453.

834 Brunet, Y., Finnigan, J.J., Raupach, M.R., 1994. A Wind-Tunnel Study of Air-Flow in 835 Waving Wheat - Single-Point Velocity Statistics. Boundary-Layer Meteorol. 70 (1-2), 95-132.

837 Collares-Pereira, M., Rabl, A., 1979. The average distribution of solar radiation-correlations 838 between diffuse and hemispherical and between daily and hourly insolation values. Sol. 839 Energy 22, 155-164.

841 Courault, D., Seguin, B., Olioso, A., 2005. Review on estimation of evapotranspiration from 842 remote sensing data: From empirical to numerical modeling approaches. Irrig. Drain. Syst. 19 843 (3), 223-249.

845 Daneshkar Arasteh, P., Tajrishy, M., 2008. Calibrating Priestley-Taylor Model to Estimate 846 Open Water Evaporation under Regional Advection Using Volume Balance Method-Case 847 Study: Chahnimeh Reservoir, Iran. J. Appl. Sci. 8 (22), 4097-4104.

849 Dupont, S., Brunet, Y., Finnigan, J.J., 2008. Large-eddy simulation of turbulent flow over a 850 forested hill: Validation and coherent structure identification. Quart. J. Roy. Meteorol. Soc. $851134(636), 1911-1929$. 
853 Feigenwinter, C., Bernhofer, C., Eichelmann, U., Heinesch, B., Hertel, M., Janous, D., Kolle, 854 O., Lagergren, F., Lindroth, A., Minerbi, S., Moderow, U., Mölder, M., Montagnani, L., 855 Queck, R., Rebmann, C., Vestin, P., Yernaux, M., Zeri, M., Ziegler, W., Aubinet, M., 2008. 856 Comparison of horizontal and vertical advective CO2 fluxes at three forest sites. Agric. For. 857 Meteorol. 148(1), 12-24.

859 Finnigan, J.J., Brunet, Y., 1995. Turbulent airflow in forests on flat and hilly terrain. In: 860 Coutts, M.P., Grace, J. (Eds.), Wind and Trees. Cambridge University Press, UK, pp. 3-40.

862 Finnigan, J.J., 2004. Advection and modelling. In: Lee, X., Massman, W., Law, B. (Eds.), 863 Handbook of Micrometeorology: A Guide for Surface Flux Measurement and Analysis. 864 Kluwer Academic Publisher, Dordrecht, pp. 209-241.

866 Finnigan, J.J., Belcher, S.E., 2004. Flow over a hill covered with a plant canopy. Quart. J. 867 Roy. Meteorol. Soc. 130 (596), 1-29.

868

869 Foken, T., Wichura, B., 1996. Tools for quality assessment of surface-based flux measurements. Agric. For. Meteorol. 78(1-2), 83-105.

871

872 Foken, T., Gockede, M., Mauder, M., Mahrt, L., Amiro, B., Munger, W., 2004. Post-field data 873 quality control. In: Lee, X., Massman, W., Law, B. (Eds.), Handbook of Micrometeorology: 874 A Guide for Surface Flux Measurement and Analysis. Kluwer Academic Publisher, 875 Dordrecht, pp. 181-208.

877 Foken, T., 2008. The energy balance closure problem - An overview. Ecol. Appl. 18 (6), 878 1351-1367.

880 Geissbühler, P., Siegwolf, R., Eugster, W., 2000. Eddy covariance measurements on mountain 881 slopes: The advantage of surface-normal sensor orientation over a vertical set-up. Boundary882 Layer Meteorol. 96 (3), 371-392. 
884 Hammerle, A., Haslwanter, A., Schmitt, M., Bahn, M., Tappeiner, U., Cernusca, 885 A., Wohlfahrt, G., 2007. Eddy covariance measurements of carbon dioxide, latent and sensible energy fluxes above a meadow on a mountain slope. Boundary-Layer Meteorol. 122 (2), 397-416.

889 Heusinkveld, B.G., Jacobs, A.F.G., Holtslag, A.A.M., Berkowicz, S.M., 2004. Surface energy

890 balance closure in an arid region: role of soil heat flux. Agric. Forest Meteorol. 122, 21-37.

892 Hiller, R., Zeeman, M.J., Eugster, W., 2008. Eddy-covariance flux measurements in the 893 complex terrain of an Alpine valley in Switzerland. Boundary-Layer Meteorol. 127 (3), 449894467.

Holst, T., Rost, J., Mayer, H., 2005. Net radiation balance for two forested slopes on opposite 897 sides of a valley. Int. J. Biometeorol. 49, 275-284.

899 Horst, T.W., Weil, J.C., 1992. Footprint Estimation for Scalar Flux Measurements in the 900 Atmospheric Surface-Layer. Boundary-Layer Meteorol. 59 (3), 279-296.

901

902 Humphreys, E.R., Black, T.A., Ethier, G.J., Drewitt, G.B., Spittlehouse, D.L., Jork, E.903 M., Nesic, Z., Livingston, N.J., 2003. Annual and seasonal variability of sensible and latent 904 heat fluxes above a coastal Douglas-fir forest, British Columbia, Canada. Agric. For. 905 Meteorol. 115 (1-2), 109-125.

907 Hunt, J.C.R., Leibovich, S., Richards, K.J., 1988. Turbulent Shear Flows over Low Hills. 908 Quart. J. Roy. Meteorol. Soc. 114 (484), 1435-1470.

910 Jackson, P.S., Hunt, J.C.R., 1975. Turbulent Wind Flow over a Low Hill. Quart. J. Roy. 911 Meteorol. Soc. 101(430), 929-955.

913 Kaimal, J.S., Finnigan, J.J., 1994. Atmospheric boundary layer flows, their structure and 914 measurement. Oxford university press, Oxford, 289 pp. 
916 Kustas, W.P., Humes, K.S., Norman, J.M., Moran, M.S., 1996. Single-and dual-source

917 modeling of surface energy fluxes with radiometric surface temperature. J. Appl. Meteorol.

$918 \quad 35,110-121$.

920 Kustas, W.P., Prueger, J.H., Hatfield, J.L., Ramalingam, K., Hipps, L.E., 2000. Variability in

921 soil heat flux from a mesquite dune site. Agric. For. Meteorol. 103, 249-264.

923 Lee, X., Finnigan, J.J., Paw U, K.T., 2004. Coordinate systems and flux bias error. In: Lee, 924 X., Massman, W.J., Law, B. (Eds.), Handbook of micrometeorology. A guide for surface flux 925 measurements and analysis. Kluwe academic publishers, pp. 33-64.

927 Lewicki, J.L., Fischer, M.L., Hilley, G.E., 2008. Six-week time series of eddy covariance 928 CO2 flux at Mammoth Mountain, California: Performance evaluation and role of 929 meteorological forcing. J. Volcanol. Geotherm. Res. 171 (3-4), 178-190.

931 Liebethal, C., Huwe, B., Foken, T., 2005. Sensitivity analysis for two ground heat flux 932 calculation approaches. Agric. For. Meteorol. 132, 253-262.

934 Massman, W.J., Lee, X., 2002. Eddy covariance flux corrections and uncertainties in long935 term studies of carbon and energy exchanges. Agric. For. Meteorol. 113 (1-4), 121-144.

937 Mekki, I., Albergel, J., Ben Mechlia, N., Voltz, M., 2006. Assessment of overland flow 938 variation and blue water production in a farmed semi-arid water harvesting catchment. Phys. 939 Chem. Earth. 31 (17), 1048-1061.

941 Moussa, R., Chahinian, N., Bocquillon, C., 2007. Distributed hydrological modelling of a 942 Mediterranean mountainous catchment - model construction and multi-site validation. J. 943 Hydrol. 337 (1-2), 35-51.

945 Olioso, A., Braud, I., Chanzy, A., Courault, D., Demarty, J., Kergoat, L., Lewan, E., Ottlé, 946 C., Prévot, L., Zhao, W. G., Calvet, J.-C., Cayrol, P., Jongschaap, R., Moulin, S., Noilhan, 
947 J., Wigneron, J.P., 2002a. SVAT modeling over the Alpilles-ReSeDA experiment: comparing

948 SVAT models over wheat fields. Agron. Sustainable Dev. 22 (6), 651-668.

950 Olioso, A., Braud, I., Chanzy, A., Demarty, J., Ducros, Y., Gaudu, J.-C., Gonzalez-Sosa, 951 E., Lewan, E., Marloie, O., Ottlé, C., Prévot, L., Thony, J.-L., Autret, H., Bethenod, 952 O., Bonnefond, J.-M., Bruguier, N., Buis, J.-P., Calvet, J.-C., Caselles, V., Chauki, H., Coll, 953 C., François, C., Goujet, R., Jongcshaap, R., Kerr, Y., King, C., Lagouarde, J.-P., Laurent, J.954 P., Lecharpentier, P., McAneney, J., Moulin, S., Rubio, E., Weiss, M., Wigneron, J.-P., 955 2002b. Monitoring energy and mass transfers during the Alpilles-ReSeDA experiment. Agron. Sustainable Dev. 22 (6), 597-610.

Poggi, D., Katul, G., 2007. An experimental investigation of the mean momentum budget inside dense canopies on narrow gentle hilly terrain. Agric. For. Meteorol. 144 (1-2), 1-13.

Raclot, D., Albergel, J., 2006. Runoff and water erosion modelling using WEPP on a

Mediterranean cultivated catchment. Phys. Chem. Earth. 31 (17), 1038-1047.

964 Rana, G., Katerji, N., 2000. Measurement and estimation of actual evapotranspiration in the

Rana, G., Ferrara, R.M., Martinelli, N., Personnic, P., Cellier, P., 2007. Estimating energy

fluxes from sloping crops using standard agrometeorological measurements and topography.

Agric. For. Meteorol. 146 (3-4), 116-133.

Raupach, M.R., Weng, W.S., Carruthers, D.J., Hunt, J.C.R., 1992. Temperature and Humidity

972 Fields and Fluxes over Low Hills. Quart. J. Roy. Meteorol. Soc. 118 (504), 191-225.

974 Raupach, M.R., Finnigan, J.J., 1997. The influence of topography on meteorological variables 975 and surface-atmosphere interactions, J. Hydrol. 190 (3-4), 182-213.

977 Rebmann, C., Göckede, M., Foken, T., Aubinet, M., Aurela, M., Berbigier, P., Bernhofer, C., 978 Buchmann, N., Carrara, A., Cescatti, A., Ceulemans, R., Clement, R., Elbers, J.A., Granier, 
979 A., Grünwald, T., Guyon, D., Havránková, K., Heinesch, B., Knohl, A., Laurila, T., Longdoz, 980 B., Marcolla, B., Markkanen, T., Miglietta, F., Moncrieff, J., Montagnani, L., Moors, E., 981 Nardino, M., Ourcival, J.M., Rambal, S., Rannik, U., Rotenberg, E., Sedlak, P., Unterhuber, 982 G., Vesala, T., Yakir, D., 2005. Quality analysis applied on eddy covariance measurements at 983 complex forest sites using footprint modelling, Theor. Appl. Climatol. 80 (2-4), 121-141.

985 Saha, R., Ghosh, P.K., Mishra, V.K., Bujarbaruah, K.M., 2007. Low-cost micro-rainwater 986 harvesting technology (Jalkund) for new livelihood of rural hill farmers. Curr. Sci. 29 (9), $987 \quad 1258-1265$.

Scott, R.L., 2010. Using watershed water balance to evaluate the accuracy of eddy covariance evaporation measurements for three semiarid ecosystems. Agric. For. Meteorol. 150 (2), 219225.

Shao, C.L., Chen, J.Q., Li, L.H., Xu, W.T., Chen, S.P., Gwen, T., Xu, J.Y., Zhang, W.L., 994 2008. Spatial variability in soil heat flux at three Inner Mongolia steppe ecosystems. Agric. For. Meteorol. 148, 1433-1443.

Stannard, D.I., Blanford, J.H., Kustas, W.P., Nichols, W.D., Amer, S.A., Schmugge, T.J., 998 Weltz, M.A., 1994. Interpretation of surface fluxes measurements in heterogeneous terrain 999 during the Monsoon '90 experiment. Water Resour. Res. 30(5), 1227-1239.

Tamura, T., Cao, S., Okuno, A., 2007. LES study of turbulent boundary layer over a smooth 1002 and a rough 2D hill model. Flow, Turbul. Combust. 79 (4), 405-432.

1004 Turnipseed, A.A., Anderson, D.E., Blanken, P.D., Baugh, W.M., Monson, R.K., 2003. 1005 Airflows and turbulent flux measurements in mountainous terrain Part 1. Canopy and local 1006 effects. Agric. For. Meteorol. 119 (1-2), 1-21.

1008 van-Dijk, A., Moene, A.F., DeBruin, H.A.R., 2004. The principles of surface flux physics: 1009 theory, practice and description of the ECPACK library. Internal report 2004/1, Meteorology 1010 and Air Quality Group, the Netherlands, Wageningen, the Netherlands 99 pp. 
1012 Wilczak, J.M., Oncley, S.P., Stage, S.A., 2001. Sonic anemometer tilt correction algorithms. 1013 Boundary-Layer Meteorol. 99 (1), 127-150.

1014

1015 Wilson, K., Goldstein, A., Falge, F., Aubinet, M., Baldocchi, D., Berbigier, P., Bernhofer, 1016 C., Ceulemans, R., Dolman, H., Field, C., Grelle, A., Ibrom, A., Law, B.E., Kowalski, 1017 A., Meyers, T., Moncrieff, J., Monson, R., Oechel, W., Tenhunen, J., Valentini, R., Verma, S., 1018 2002. Energy balance closure at FLUXNET sites. Agric. For. Meteorol. 113 (1-4), 223-243.

1020 Zitouna Chebbi, R., 2009. Observing and characterising water and energy exchanges within 1021 the soil-plant-atmosphere continuum under condition of hilly relief. The case study of the 1022 Kamech catchment, Cap Bon Peninsula, Tunisia. Ph.D. thesis from the Montpellier SupAgro 1023 graduate School of Agronomy, Montpellier, France 292 pp. 


\section{Figure captions}

Figure 1: Location of Tunisia within the Mediterranean Basin (top); location the Kamech catchment within the Cap Bon Peninsula, northeastern Tunisia (bottom left); and a threedimensional view of the Kamech catchment with the corresponding perimeter in white (bottom right).

Figure 2: Topography of the Kamech catchment deduced from a 4-m spatial resolution digital elevation model (DEM). Altitude above sea level is given in metres (right greyscale bar). The thick black line represents the catchment outline. The altitude contour lines (thin black lines) are drawn every $10 \mathrm{~m}$. The positions of the meteorological station $(\mathrm{M})$ and of the flux stations on fields $\mathrm{A}$ and $\mathrm{C}$ are represented by the white circles.

Figure 3: Detailed view of the topography near fields A and C within the Kamech catchment. Altitude above sea level is given in metres (right greyscale bar). The thick black lines represent the field limits. The altitude contour lines (thin black lines) are drawn every $5 \mathrm{~m}$. The positions of the flux stations are represented by white circles.

Figure 4: Distribution of the wind direction throughout the experiment for the years 2004 (left) and 2006 (right). The two wind roses indicate the occurrence of wind speeds for 16 wind directions.

Figure 5: Distributions of the footprint dimensions for the fields A (top line; datasets A04 and A06 are merged) and C (bottom line; dataset C06). The footprint lengths (along the wind direction) are in the left column, and the footprint widths (across the wind direction) are in the right column. Median values are indicated by vertical black lines. Footprint dimensions (x-axis) are in metres. The $y$-axis is the number of 30-minute intervals belonging to each class.

Figure 6: Determination of the wind-oriented topography for fields A (top line) and C (bottom line), for the south winds (left column, yaw angle $=180^{\circ}$ from north clockwise) and northwest winds (right column, yaw angle $=320^{\circ}$ from north clockwise). The points are the DEMderived altitude data extracted within a 120-m-wide rectangle, oriented along each wind direction ( $\mathrm{S}$ or NW) and passing through the flux stations (A or C). The $\mathrm{x}$-axis is the distance from the flux stations $(\mathrm{x}=0$, vertical dotted line) along the wind direction, where the wind blows from the negative to positive $\mathrm{x}$ values (metres). The $\mathrm{y}$-axis is the altitude above sea level (metres). The vertical arrows represent the limits of the catchment. A topographical plane was fitted against these altitude data for determining the wind oriented topographical slopes equivalent to the planar fit pitch and roll angles. The thick lines represent the alongwind (pitch) slopes calculated with a 360-m-long and 120-m-wide wind-oriented rectangle. The insets are zoom-ins centred on each field, showing the local topography.

Figure 7: Evolution of the wind-oriented topography (along-wind slope - equivalent to pitch angle - and across wind slope - equivalent to roll angles - on y-axis) with respect to the wind direction (yaw angle as $\mathrm{x}$-axis, $0^{\circ}$ is north, $90^{\circ}$ is east) for fields $\mathrm{A}$ (thick lines) and $\mathrm{C}$ (thin lines). The solid lines represent the pitch angles, and the dashed lines represent the roll angles. The slope angles are calculated with a $1^{\circ}$ yaw angle step. 
1074 Figure 8a: Compared evolution of the planar fit derived pitch angles and the topographical 1075 along-wind slopes (y-axis) with respect to the wind direction (x-axis, $0^{\circ}$ is north, $90^{\circ}$ is east) 1076 for fields A (top) and C (bottom). The continuous curves represent the topographical along1077 wind slope, as derived from the DEM data (same as Fig. 7). The planar fit-derived pitch 1078 angles evaluated over the entire datasets (A04, A06, C06) and for each wind sector (south and 1079 northwest) are represented by the portions of discontinuous curves (dotted lines for year 2004, 1080 dashed lines for year 2006); they are labelled as the "PF mean pitch". The planar fit-derived 1081 pitch angles evaluated for each day and each wind sector are represented by symbols 1082 (triangles for the year 2004, circles for the year 2006), where each symbol represents a day or 1083 a portion of the day during which the wind direction was within a wind sector; they are 1084 labelled as the "PF pitch".

1085

1086 Figure 8b: Compared evolution of the planar fit derived roll angles and topographical cross1087 wind slopes (y-axis) with respect to the wind direction (x-axis, $0^{\circ}$ is north, $90^{\circ}$ is east) for 1088 fields A (top) and C (bottom). The continuous curves represent the topographical across-wind 1089 slope, as derived from the DEM data (same as Fig. 7). The planar fit-derived roll angles 1090 evaluated over the entire datasets (A04, A06, C06) and for each wind sector (south and 1091 northwest) are represented by the portions of the discontinuous curves (dotted lines for the 1092 year 2004, dashed lines for the year 2006); they are labelled as the "PF mean roll". The planar 1093 fit-derived roll angles evaluated for each day and each wind sector are represented by symbols 1094 (triangles for the year 2004, circles for the year 2006), where each symbol represents a day or 1095 a portion of the day during which the wind direction was within a wind sector; they are 1096 labelled as the "PF roll".

1097

1098 Figure 9: Energy balance closure for the datasets A04 (top line) and C06 (bottom line) and for 1099 the upward winds (left column) and downward winds (right column). The available energy $1100 \mathrm{Rn}-\mathrm{G}\left(\mathrm{W} \mathrm{m}^{-2}\right)$ is on the $\mathrm{x}$-axis, and the convective energy $\mathrm{H}+\mathrm{LE}\left(\mathrm{W} \mathrm{m}^{-2}\right)$ is on the $\mathrm{y}$-axis. The 1101 data correspond to the 30-minute intervals. The dashed line is the 1:1 line, and the continuous 1102 line is the $y$-axis data versus $\mathrm{x}$-axis data regression line (regression coefficients are given in 1103 Table 3).

1104 


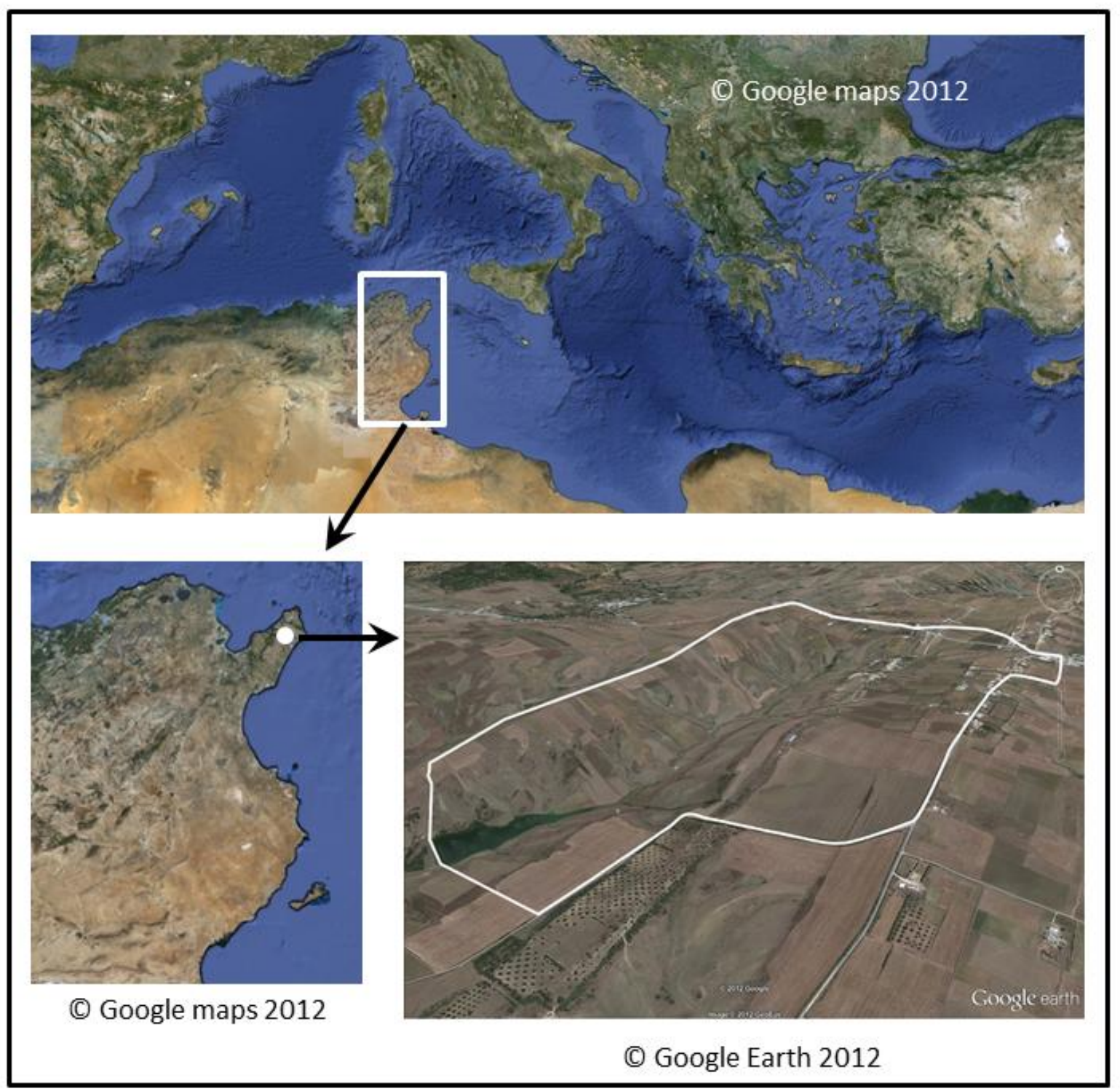

1106

1107

1108 Figure 1: Location of Tunisia within the Mediterranean Basin (top); location the Kamech 1109 catchment within the Cap Bon Peninsula, northeastern Tunisia (bottom left); and a three1110 dimensional view of the Kamech catchment with the corresponding perimeter in white 1111 (bottom right). 


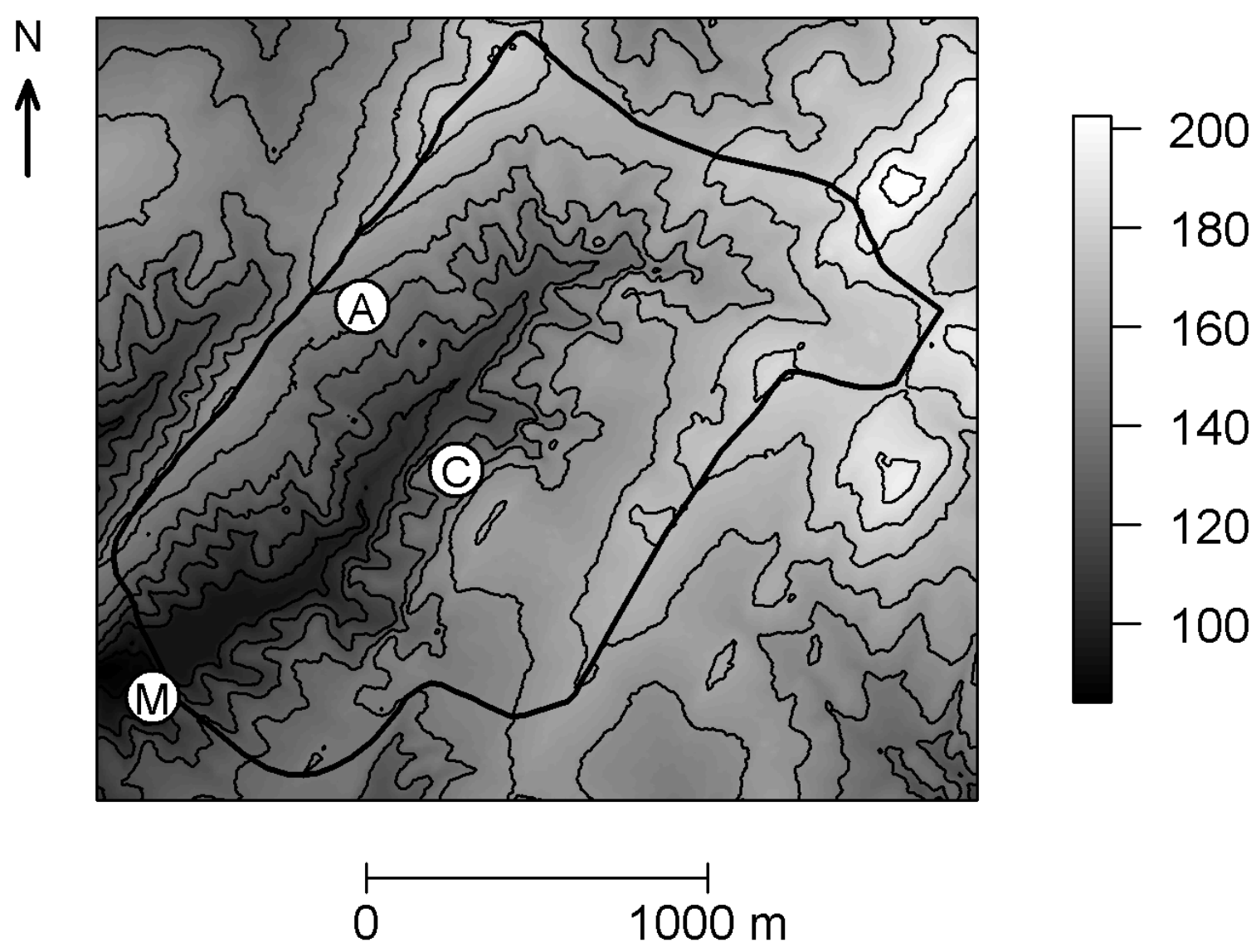

1114

Figure 2: Topography of the Kamech catchment deduced from a 4-m spatial resolution digital elevation model (DEM). Altitude above sea level is given in metres (right greyscale bar). The thick black line represents the catchment outline. The altitude contour lines (thin black lines) are drawn every $10 \mathrm{~m}$. The positions of the meteorological station $(\mathrm{M})$ and of the flux stations on fields $\mathrm{A}$ and $\mathrm{C}$ are represented by the white circles. 

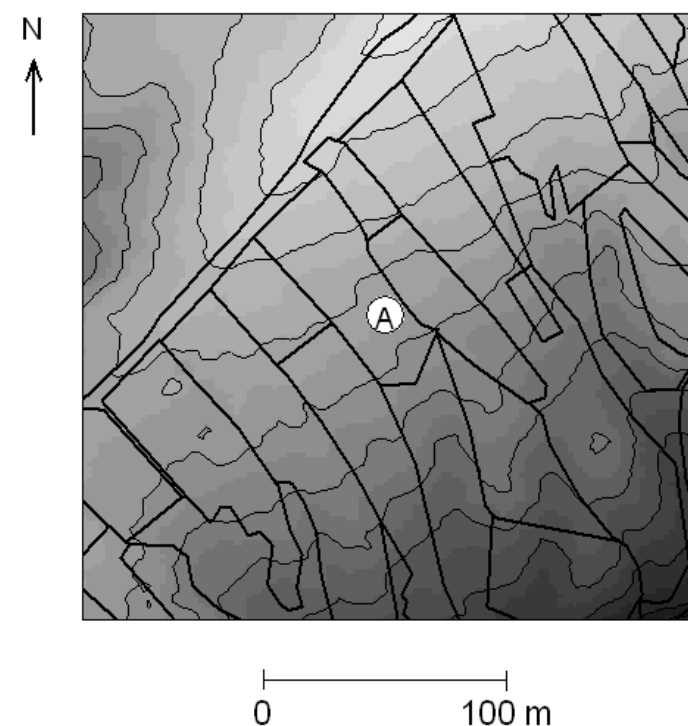
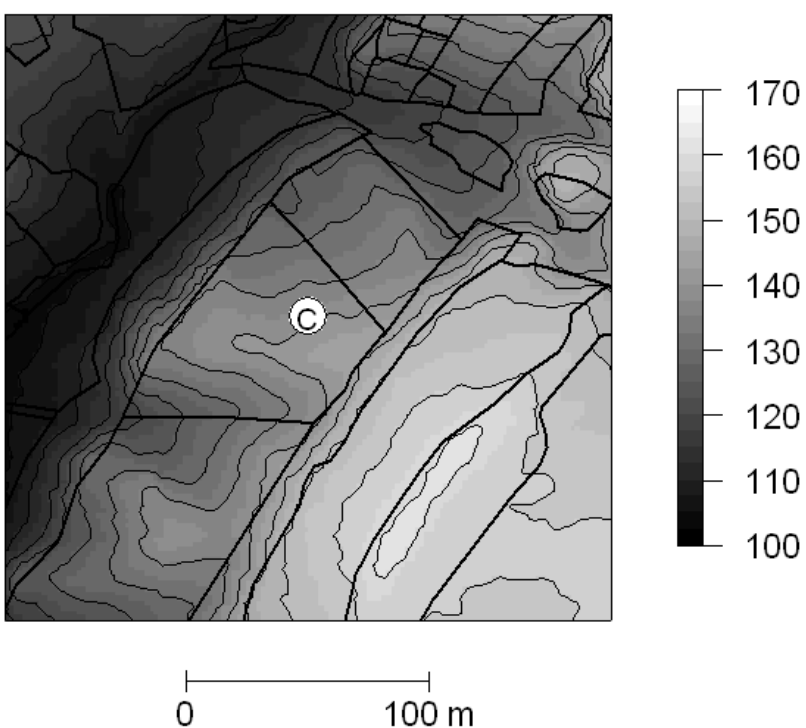

1124

1125

1126 Figure 3: Detailed view of the topography near fields A and C within the Kamech catchment.

1127 Altitude above sea level is given in metres (right greyscale bar). The thick black lines

1128 represent the field limits. The altitude contour lines (thin black lines) are drawn every $5 \mathrm{~m}$.

1129 The positions of the flux stations are represented by white circles. 

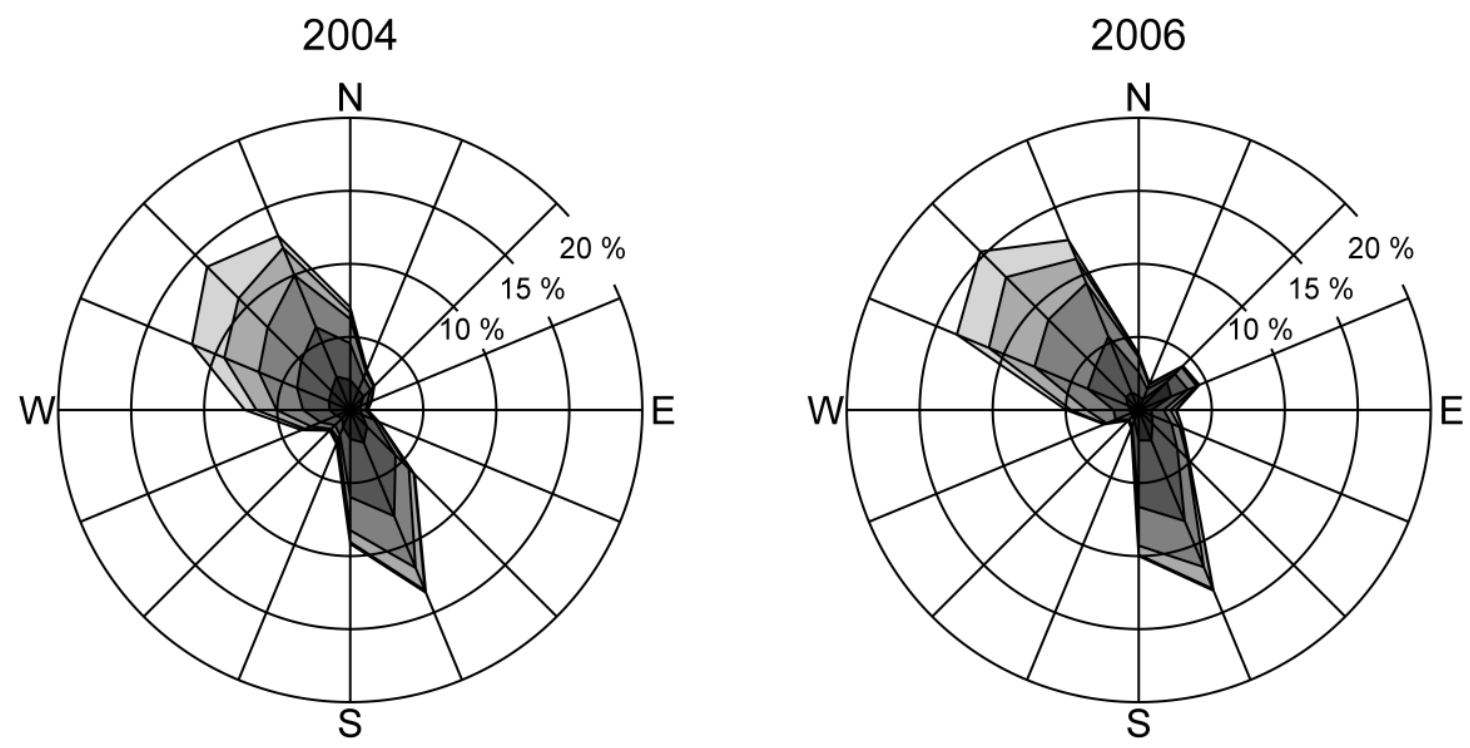

$$
\square \text { 0-2 } \square \text { 2-4 } \square \text { 4-6 } \square \text { 6-8 } \square>8
$$

1134

1135 Figure 4: Distribution of the wind direction throughout the experiment for the years 2004 1136 (left) and 2006 (right). The two wind roses indicate the occurrence of wind speeds for 16 wind 1137 directions. 
length (m)
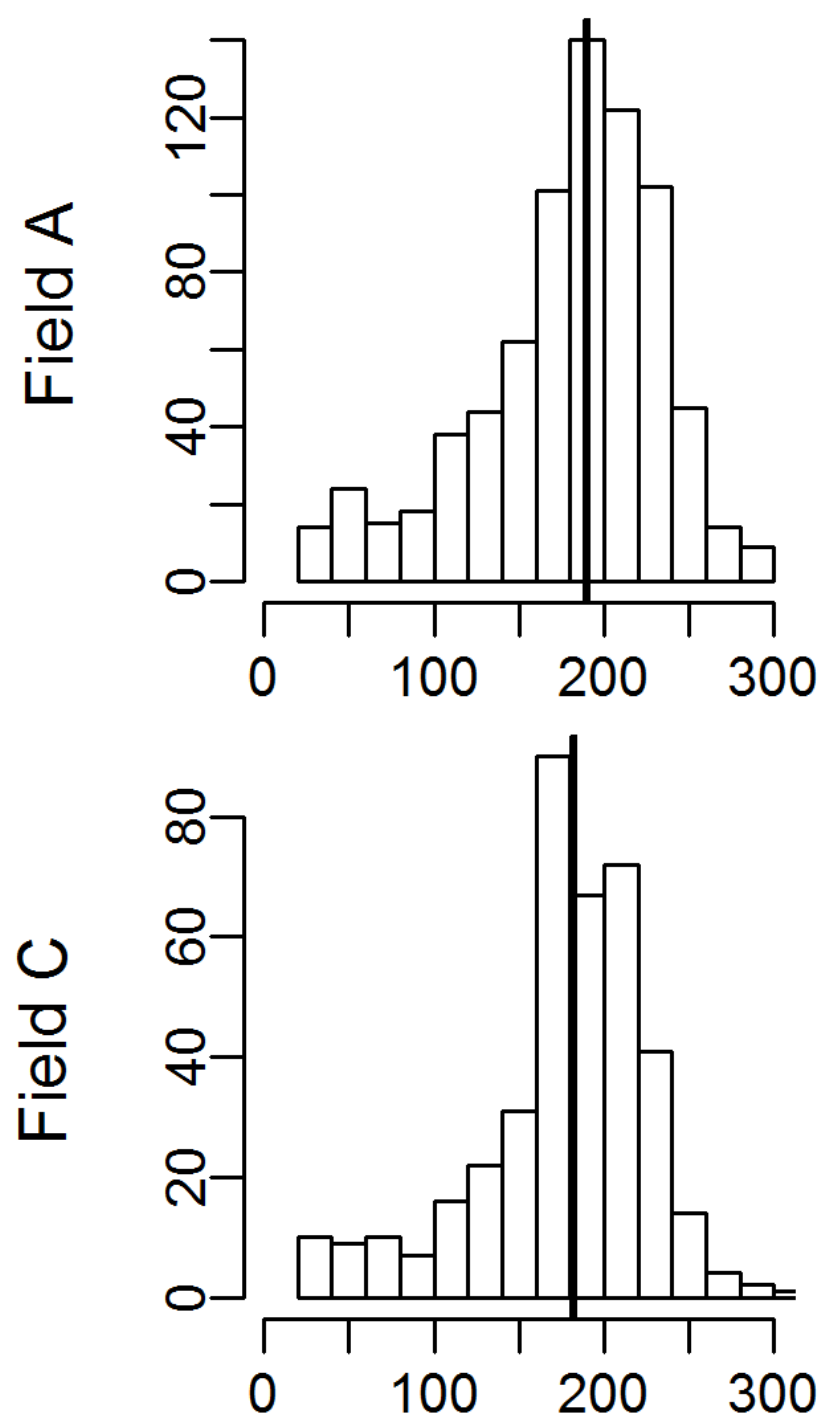

width (m)
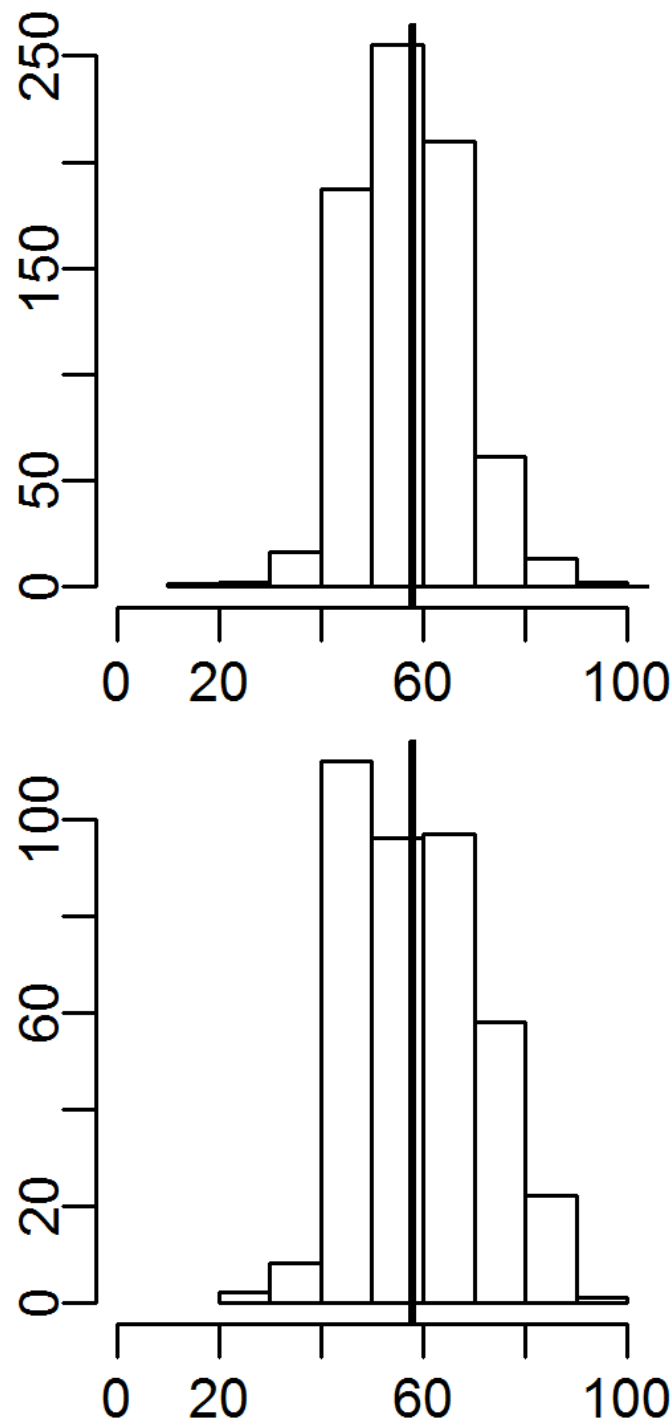

Figure 5: Distributions of the footprint dimensions for the fields A (top line; datasets A04 and A06 are merged) and $\mathrm{C}$ (bottom line; dataset C06). The footprint lengths (along the wind direction) are in the left column, and the footprint widths (across the wind direction) are in the right column. Median values are indicated by vertical black lines. Footprint dimensions (x-axis) are in metres. The $y$-axis is the number of 30-minute intervals belonging to each class. 

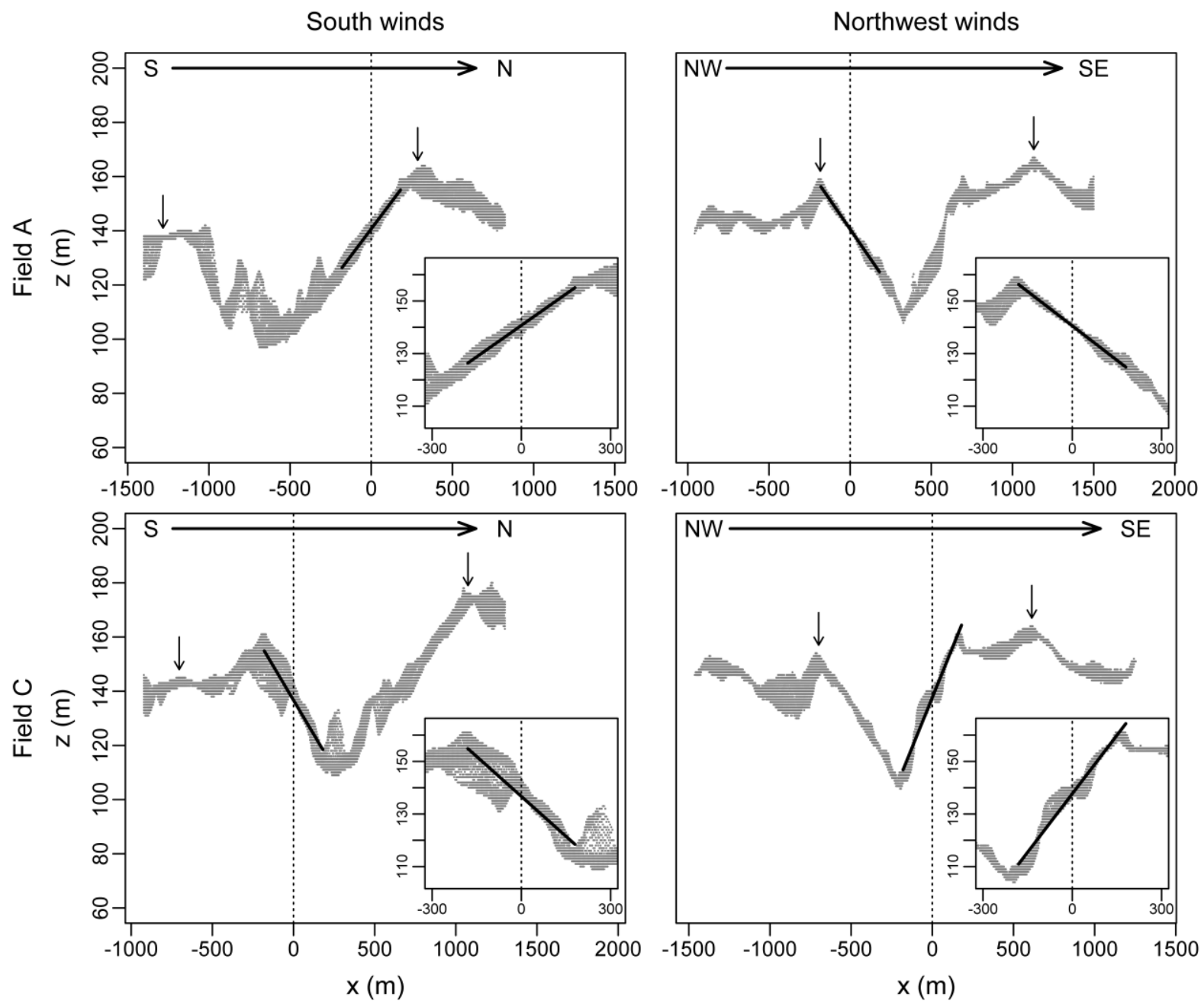

Figure 6: Determination of the wind-oriented topography for fields A (top line) and C (bottom line), for the south winds (left column, yaw angle $=180^{\circ}$ from north clockwise) and northwest winds (right column, yaw angle $=320^{\circ}$ from north clockwise). The points are the DEMderived altitude data extracted within a 120-m-wide rectangle, oriented along each wind direction ( $\mathrm{S}$ or NW) and passing through the flux stations (A or $\mathrm{C}$ ). The $\mathrm{x}$-axis is the distance from the flux stations ( $\mathrm{x}=0$, vertical dotted line) along the wind direction, where the wind blows from the negative to positive $x$ values (metres). The $y$-axis is the altitude above sea level (metres). The vertical arrows represent the limits of the catchment. A topographical plane was fitted against these altitude data for determining the wind oriented topographical slopes equivalent to the planar fit pitch and roll angles. The thick lines represent the alongwind (pitch) slopes calculated with a 360-m-long and 120-m-wide wind-oriented rectangle. The insets are zoom-ins centred on each field, showing the local topography. 


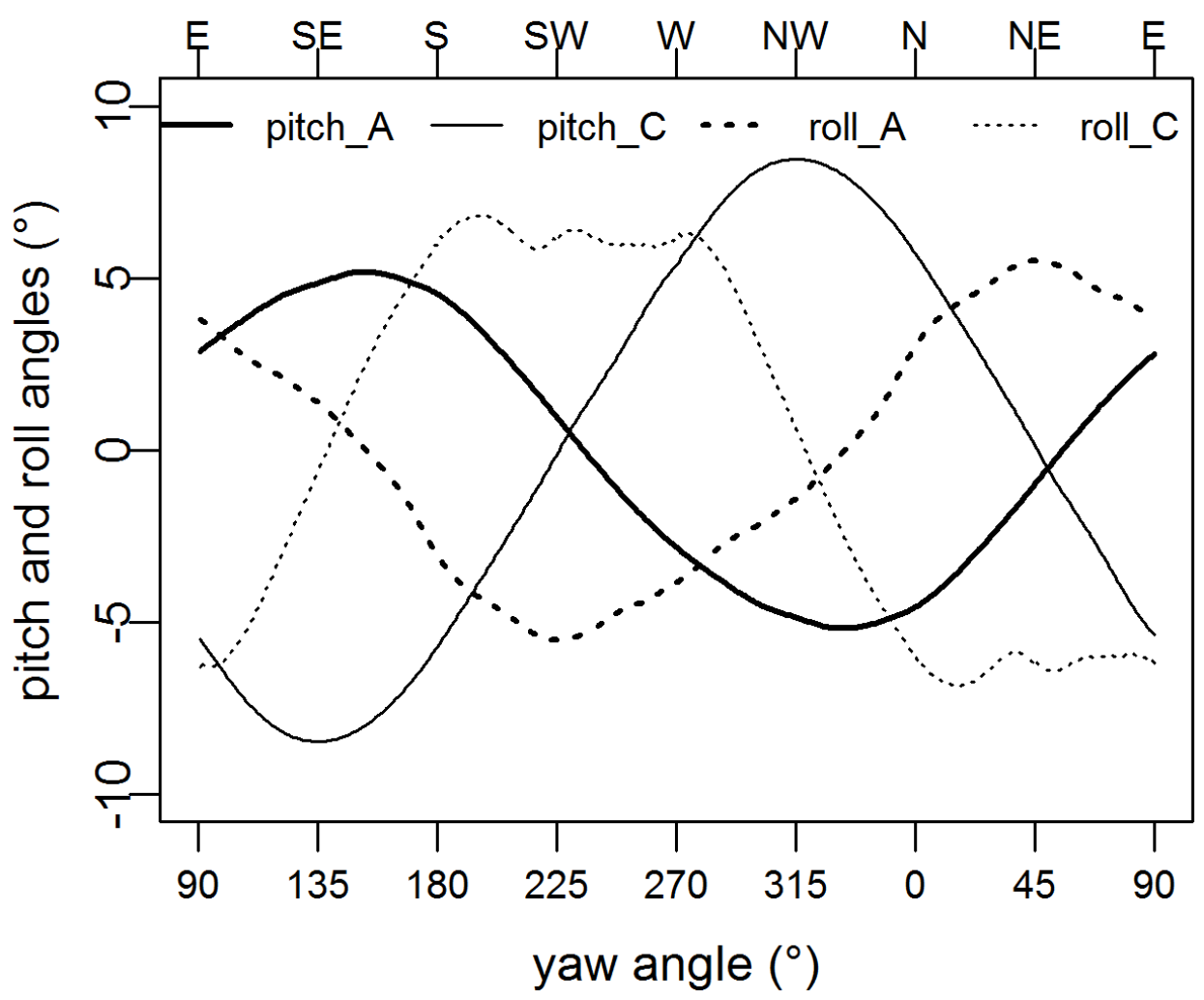

1168 Figure 7: Evolution of the wind-oriented topography (along-wind slope - equivalent to pitch 1169 angle - and across wind slope - equivalent to roll angles - on y-axis) with respect to the wind 1170 direction (yaw angle as $\mathrm{X}$-axis, $0^{\circ}$ is north, $90^{\circ}$ is east) for fields $\mathrm{A}$ (thick lines) and $\mathrm{C}$ (thin 1171 lines). The solid lines represent the pitch angles, and the dashed lines represent the roll angles. 1172 The slope angles are calculated with a $1^{\circ}$ yaw angle step. 

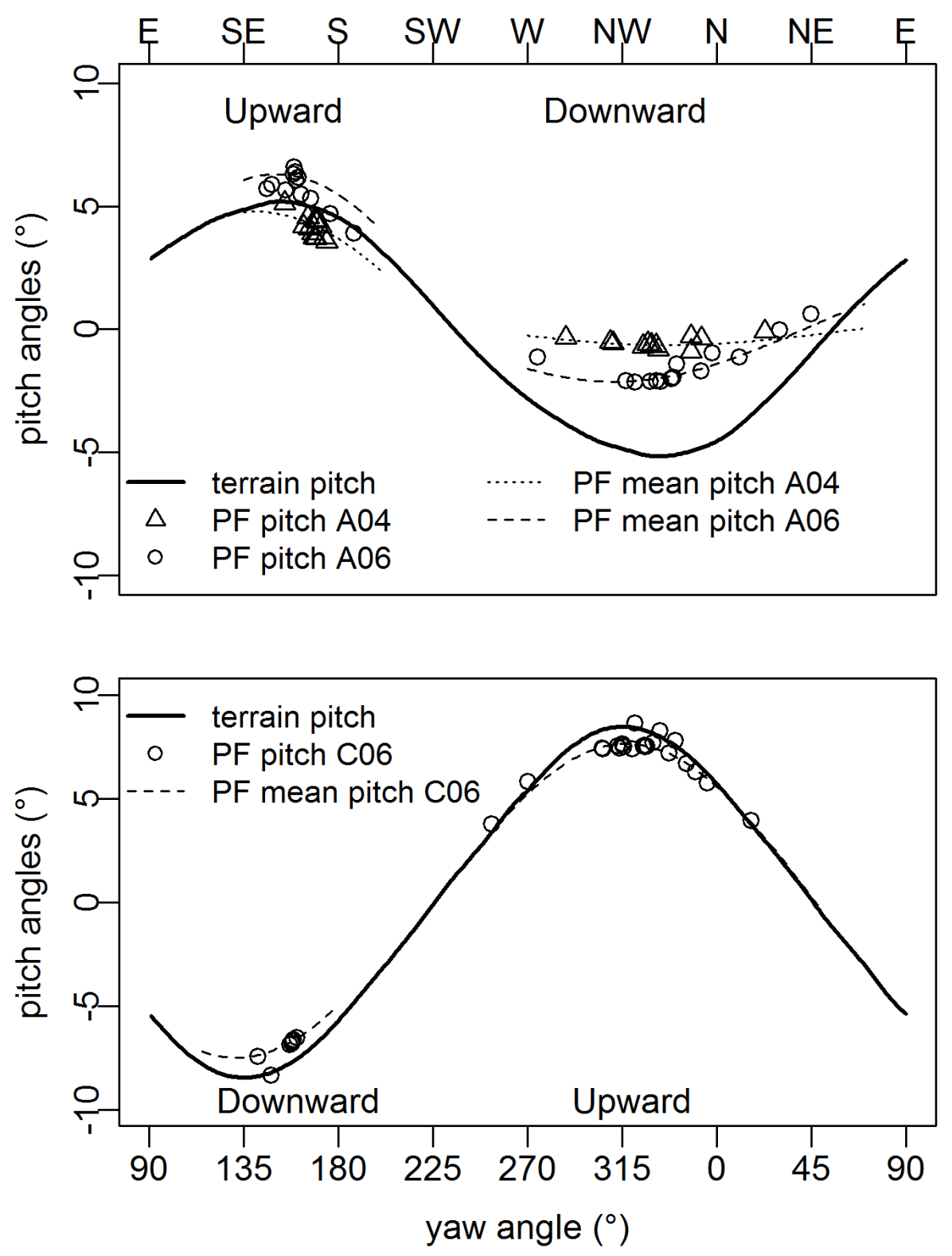

1177 Figure 8a: Compared evolution of the planar fit derived pitch angles and the topographical 1178 along-wind slopes (y-axis) with respect to the wind direction (x-axis, $0^{\circ}$ is north, $90^{\circ}$ is east) 1179 for fields A (top) and C (bottom). The continuous curves represent the topographical along1180 wind slope, as derived from the DEM data (same as Fig. 7). The planar fit-derived pitch angles evaluated over the entire datasets (A04, A06, C06) and for each wind sector (south and northwest) are represented by the portions of discontinuous curves (dotted lines for year 2004, dashed lines for year 2006); they are labelled as the "PF mean pitch". The planar fit-derived pitch angles evaluated for each day and each wind sector are represented by symbols (triangles for the year 2004, circles for the year 2006), where each symbol represents a day or a portion of the day during which the wind direction was within a wind sector; they are 

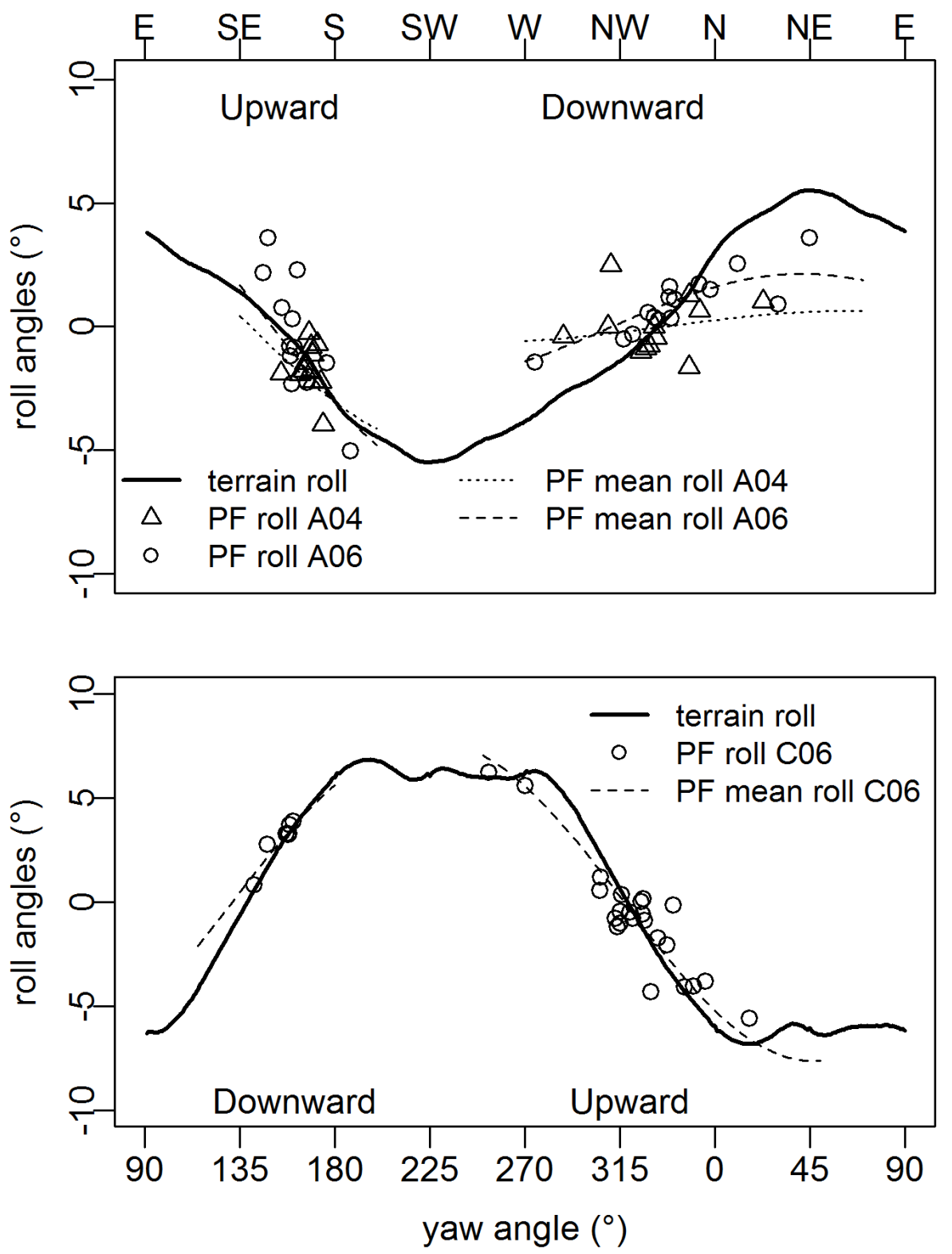

1193 Figure 8b: Compared evolution of the planar fit derived roll angles and topographical cross1194 wind slopes (y-axis) with respect to the wind direction (x-axis, $0^{\circ}$ is north, $90^{\circ}$ is east) for 1195 fields A (top) and C (bottom). The continuous curves represent the topographical across-wind 1196 slope, as derived from the DEM data (same as Fig. 7). The planar fit-derived roll angles 1197 evaluated over the entire datasets (A04, A06, C06) and for each wind sector (south and 1198 northwest) are represented by the portions of the discontinuous curves (dotted lines for the 1199 year 2004, dashed lines for the year 2006); they are labelled as the "PF mean roll". The planar 1200 fit-derived roll angles evaluated for each day and each wind sector are represented by symbols 1201 (triangles for the year 2004, circles for the year 2006), where each symbol represents a day or 1202 a portion of the day during which the wind direction was within a wind sector; they are labelled as the "PF roll". 

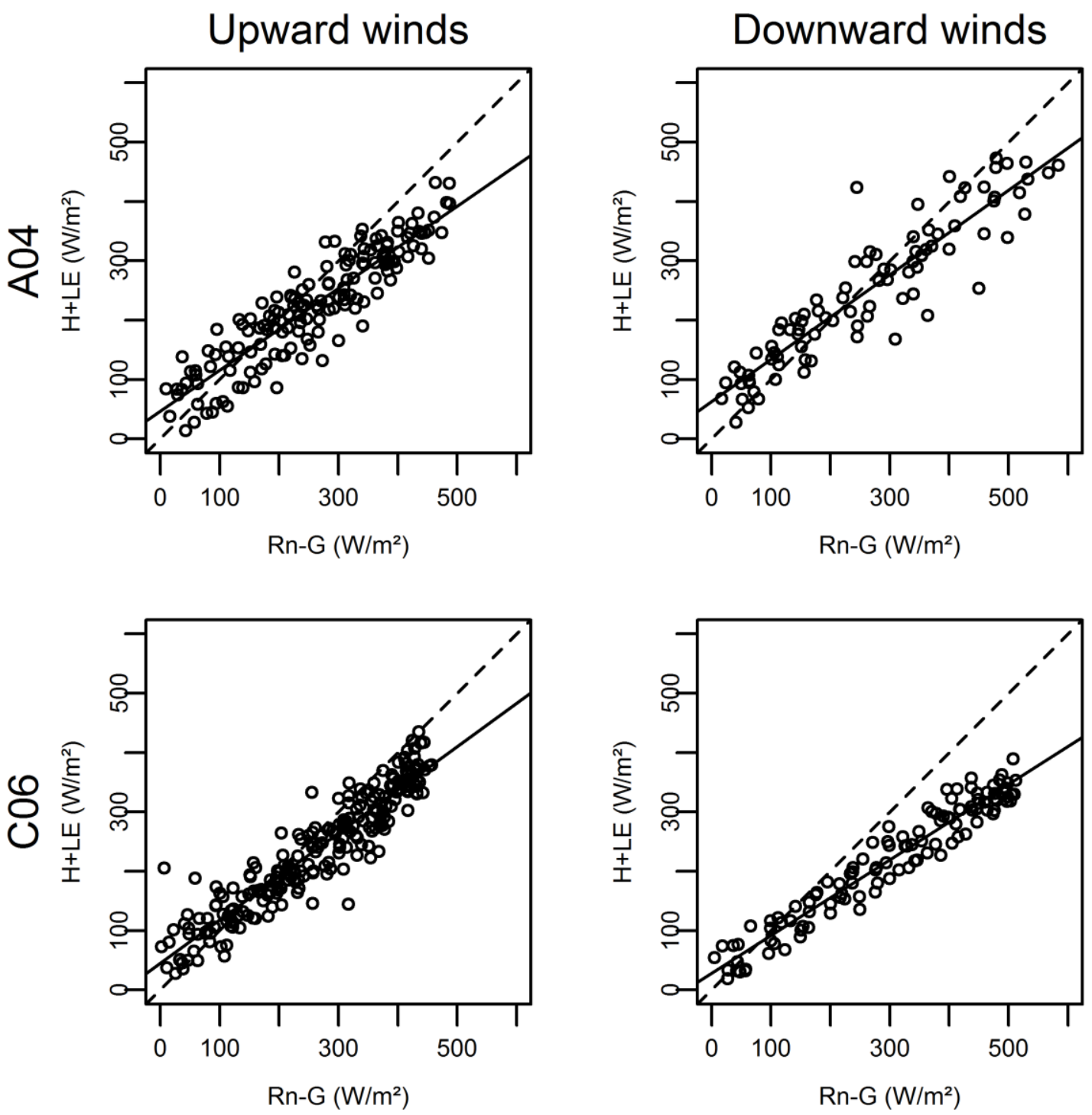

1207

1208

1209

1210

1211

1212

1213

1214

1215

Figure 9: Energy balance closure for the datasets A04 (top line) and C06 (bottom line) and for the upward winds (left column) and downward winds (right column). The available energy $\mathrm{Rn}-\mathrm{G}\left(\mathrm{W} \mathrm{m}^{-2}\right)$ is on the $\mathrm{x}$-axis, and the convective energy $\mathrm{H}+\mathrm{LE}\left(\mathrm{W} \mathrm{m}^{-2}\right)$ is on the $\mathrm{y}$-axis. The data correspond to the 30-minute intervals. The dashed line is the 1:1 line, and the continuous line is the $\mathrm{y}$-axis data versus $\mathrm{x}$-axis data regression line (regression coefficients are given in Table 3). 


\section{Table captions}

1217

1218 Table 1: Listing of the instruments that were deployed for each flux station in fields A and C 1219 for the years 2004 and 2006.

1220

1221

1222

1223

1224

1225

1226

1227

1228

1229

1230

1231

1232

1233

1234

1235

1236

1237

1238

1239

Table 2: Results from the quality control on the turbulent fluxes. The steady-state (ST) test is applied to the friction velocity $\left(\mathrm{u}_{*} \propto \overline{u^{\prime} w^{\prime}}\right)$, sensible heat flux $\left(\mathrm{H} \propto \overline{T^{\prime} w^{\prime}}\right)$ and latent heat flux $\left(\lambda \mathrm{E} \propto \overline{q^{\prime} w^{\prime}}\right.$ ). The integral turbulence characteristics (ITC) test compares the flux-variance similarities to those given by the Monin-Obukhov similarity theory. For both the ST and ITC tests, the table gives the proportion of the data belonging to the three quality classes: high quality (ST and ITC values between 0 and 0.3 ), good quality (ST and ITC values between 0.3 and 1.0) and data not meeting the quality requirements (ST and ITC values greater than 1.0).

Table 3: Statistical indicators for characterising the energy balance closure through the comparison of convective energy $(\mathrm{CE}=\mathrm{H}+\lambda \mathrm{E})$ as the $\mathrm{y}$-axis variable against the available energy $(\mathrm{AE}=\mathrm{Rn}-\mathrm{G})$ as the $\mathrm{x}$-axis variables. $\mathrm{N}$ is the data number. Terms a and $\mathrm{b}$ are, respectively the slope and the intercept of the $y=a x+b$ linear regression (continuous lines on Fig. 9). $\mathrm{R}^{2}$ is the coefficient of determination between $y$ and $\mathrm{x}$. RMSD is the root mean square difference between $y$ and $x$. URMSD is the unsystematic RMSD, defined as the scattering around the $y=a x+b$ linear regression. EBR is the energy balance ratio defined as $\mathrm{EBR}=\mathrm{CE} / \mathrm{AE}$. EB-RES is the energy balance residual, defined as EB-RES $=\mathrm{AE}-\mathrm{CE}$. The metrics used here were selected from among those reviewed by Kustas et al. (1996) and Wilson et al. (2002). 


\begin{tabular}{|l|l|l|l|l|l|}
\hline Instrument & $\begin{array}{l}\text { Field A } \\
\text { Year 2004 }\end{array}$ & $\begin{array}{l}\text { Field A } \\
\text { Year 2006 }\end{array}$ & $\begin{array}{l}\text { Field C } \\
\text { Year 2006 }\end{array}$ & $\begin{array}{l}\text { Frequency } \\
\text { of } \\
\text { acquisition }\end{array}$ & $\begin{array}{l}\text { Frequency } \\
\text { of } \\
\text { storage }\end{array}$ \\
\hline Data logger & CR23X (Campbell Scientific Inc., USA) & & \\
\hline $\begin{array}{l}\text { Sonic } \\
\text { anemometer }\end{array}$ & $\begin{array}{l}\text { CSAT3 } \\
\text { (Campbell } \\
\text { Scientific, USA) }\end{array}$ & $\begin{array}{l}\text { Young-81000V } \\
\text { (R.M. Young, } \\
\text { USA) }\end{array}$ & $10 \mathrm{~Hz}$ & $10 \mathrm{~Hz}$ \\
\hline $\begin{array}{l}\text { Krypton } \\
\text { hygrometer }\end{array}$ & $\begin{array}{l}\text { KH20 } \\
\text { (Campbell } \\
\text { Scientific, USA) }\end{array}$ & $\begin{array}{l}\text { KH20 } \\
\text { (Campbell } \\
\text { Scientific, USA) }\end{array}$ & $10 \mathrm{~Hz}$ & $10 \mathrm{~Hz}$ \\
\hline $\begin{array}{l}\text { Net } \\
\text { radiometer }\end{array}$ & NR-lite (Kipp \& Zonen, The Netherlands) & $1 \mathrm{~s}$ & $30 \mathrm{mn}$ \\
\hline $\begin{array}{l}\text { Soil heat } \\
\text { flux sensors }\end{array}$ & Three HFP01 (Hukseflux, The Netherlands) & $1 \mathrm{~s}$ & $30 \mathrm{mn}$ \\
\hline $\begin{array}{l}\text { Thermo- } \\
\text { hygrometer } \\
\text { probe }\end{array}$ & HMP45C (Vaisala, Finland) & $1 \mathrm{~s}$ & $30 \mathrm{mn}$ \\
\hline
\end{tabular}

1243 Table 1: Listing of the instruments that were deployed for each flux station in fields A and C 1244 for the years 2004 and 2006. 


\begin{tabular}{|c|c|c|c|c|c|c|}
\hline & \multicolumn{3}{|c|}{$\mathrm{ST}$} & \multicolumn{3}{c|}{$\mathrm{ITC}$} \\
\hline & $\overline{u^{\prime} w^{\prime}}$ & $\overline{T^{\prime} w^{\prime}}$ & $\overline{q^{\prime} w^{\prime}}$ & $\sigma_{w} / u_{*}$ & $\sigma_{u} / u_{*}$ & $\sigma_{T} / T_{*}$ \\
\hline$<0.3$ & $96 \%$ & $96 \%$ & $70 \%$ & $99 \%$ & $95 \%$ & $63 \%$ \\
\hline $0.3-1$ & $3 \%$ & $2 \%$ & $16 \%$ & $1 \%$ & $4 \%$ & $34 \%$ \\
\hline$>1.0$ & $2 \%$ & $2 \%$ & $14 \%$ & $0 \%$ & $0 \%$ & $2 \%$ \\
\hline
\end{tabular}

1251 Table 2: Results from the quality control on the turbulent fluxes. The steady-state (ST) test is 1252 applied to the friction velocity $\left(\mathrm{u}_{*} \propto \overline{u^{\prime} w^{\prime}}\right)$, sensible heat flux $\left(\mathrm{H} \propto \overline{T^{\prime} w^{\prime}}\right)$ and latent heat flux $1253\left(\lambda \mathrm{E} \propto \overline{q^{\prime} w^{\prime}}\right)$. The integral turbulence characteristics (ITC) test compares the flux-variance 1254 similarities to those given by the Monin-Obukhov similarity theory. For both the ST and ITC 1255 tests, the table gives the proportion of the data belonging to the three quality classes: high 1256 quality (ST and ITC values between 0 and 0.3 ), good quality (ST and ITC values between 0.3 1257 and 1.0) and data not meeting the quality requirements (ST and ITC values greater than 1.0). 


\begin{tabular}{|l|c|c|c|c|}
\cline { 2 - 5 } \multicolumn{1}{c|}{} & \multicolumn{2}{c|}{ A04 } & \multicolumn{2}{c|}{ C66 } \\
\cline { 2 - 5 } \multicolumn{1}{c|}{} & $\begin{array}{c}\text { Upward } \\
\text { flows }\end{array}$ & $\begin{array}{c}\text { Downward } \\
\text { flows }\end{array}$ & $\begin{array}{c}\text { Upward } \\
\text { flows }\end{array}$ & $\begin{array}{c}\text { Downward } \\
\text { flows }\end{array}$ \\
\hline $\mathrm{N}(-)$ & 155 & 99 & 233 & 120 \\
\hline Slope a (-) & 0.69 & 0.71 & 0.73 & 0.64 \\
\hline Intercept b $\left(\mathrm{W} \mathrm{m}^{-2}\right)$ & 47.0 & 63.3 & 44.8 & 28.2 \\
\hline $\mathrm{R}^{2}(-)$ & 0.82 & 0.84 & 0.88 & 0.93 \\
\hline RMSD $\left(\mathrm{W} \mathrm{m}^{-2}\right)$ & 63.7 & 65.5 & 55.6 & 100.9 \\
\hline URMSD $\left(\mathrm{W} \mathrm{m}^{-2}\right)$ & 39.6 & 47.4 & 34.9 & 25.6 \\
\hline EBR $(-)$ & 0.87 & 0.95 & 0.90 & 0.73 \\
\hline EB-RES $\left(\mathrm{W} \mathrm{m}^{-2}\right)$ & 32.7 & 12.2 & 26.9 & 81.2 \\
\hline
\end{tabular}

1261 Table 3: Statistical indicators for characterising the energy balance closure through the 1262 comparison of convective energy $(\mathrm{CE}=\mathrm{H}+\lambda \mathrm{E})$ as the $\mathrm{y}$-axis variable against the available energy $(\mathrm{AE}=\mathrm{Rn}-\mathrm{G})$ as the $\mathrm{x}$-axis variables. $\mathrm{N}$ is the data number. Terms $\mathrm{a}$ and $\mathrm{b}$ are, respectively the slope and the intercept of the $y=a x+b$ linear regression (continuous lines on Fig. 9). $\mathrm{R}^{2}$ is the coefficient of determination between $y$ and $\mathrm{x}$. RMSD is the root mean square difference between $y$ and $x$. URMSD is the unsystematic RMSD, defined as the scattering around the $y=a x+b$ linear regression. $E B R$ is the energy balance ratio defined as $\mathrm{EBR}=\mathrm{CE} / \mathrm{AE}$. EB-RES is the energy balance residual, defined as EB-RES $=\mathrm{AE}-\mathrm{CE}$. The Wilson et al. (2002). 
Figure
Click here to download high resolution image

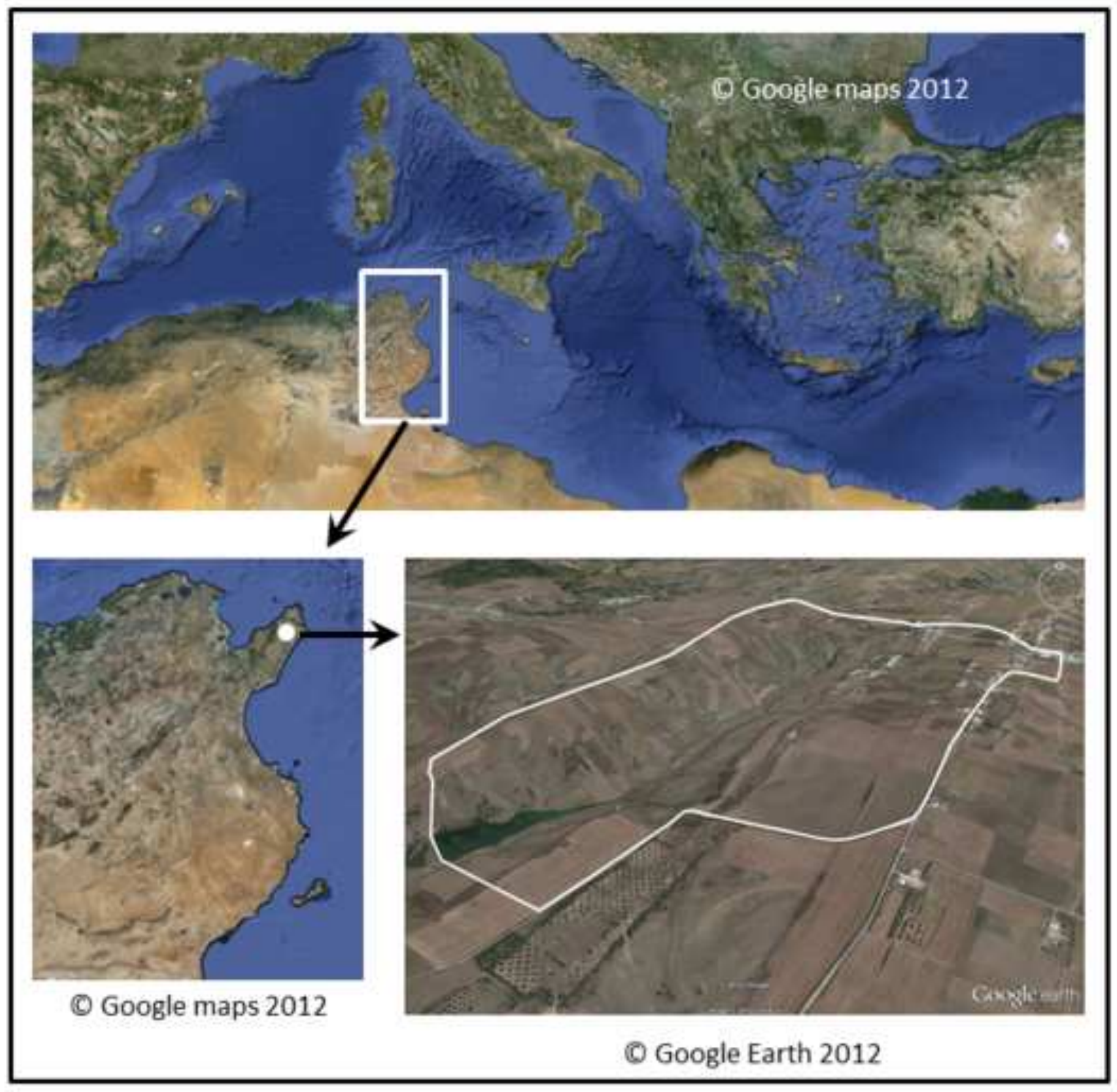



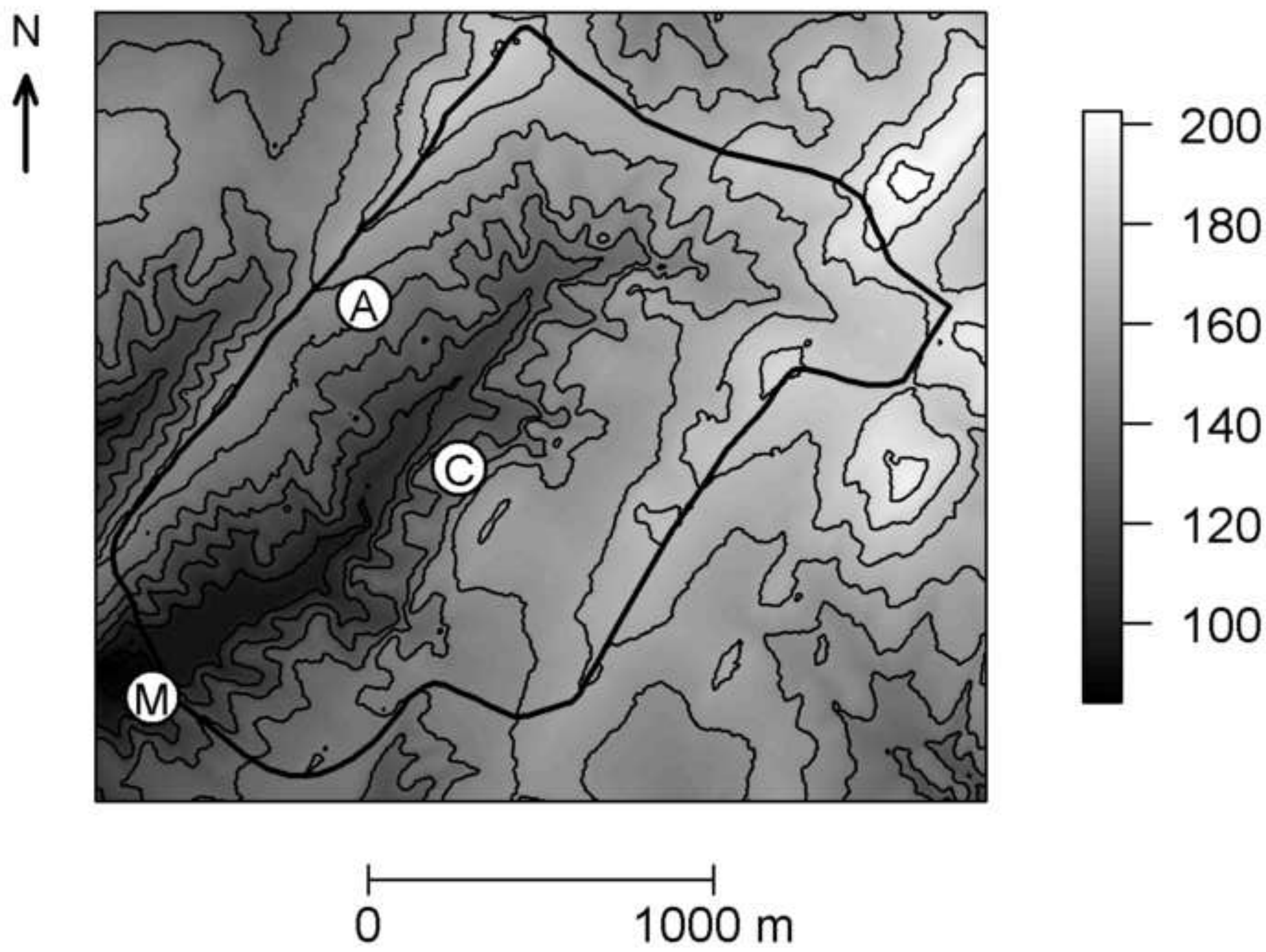

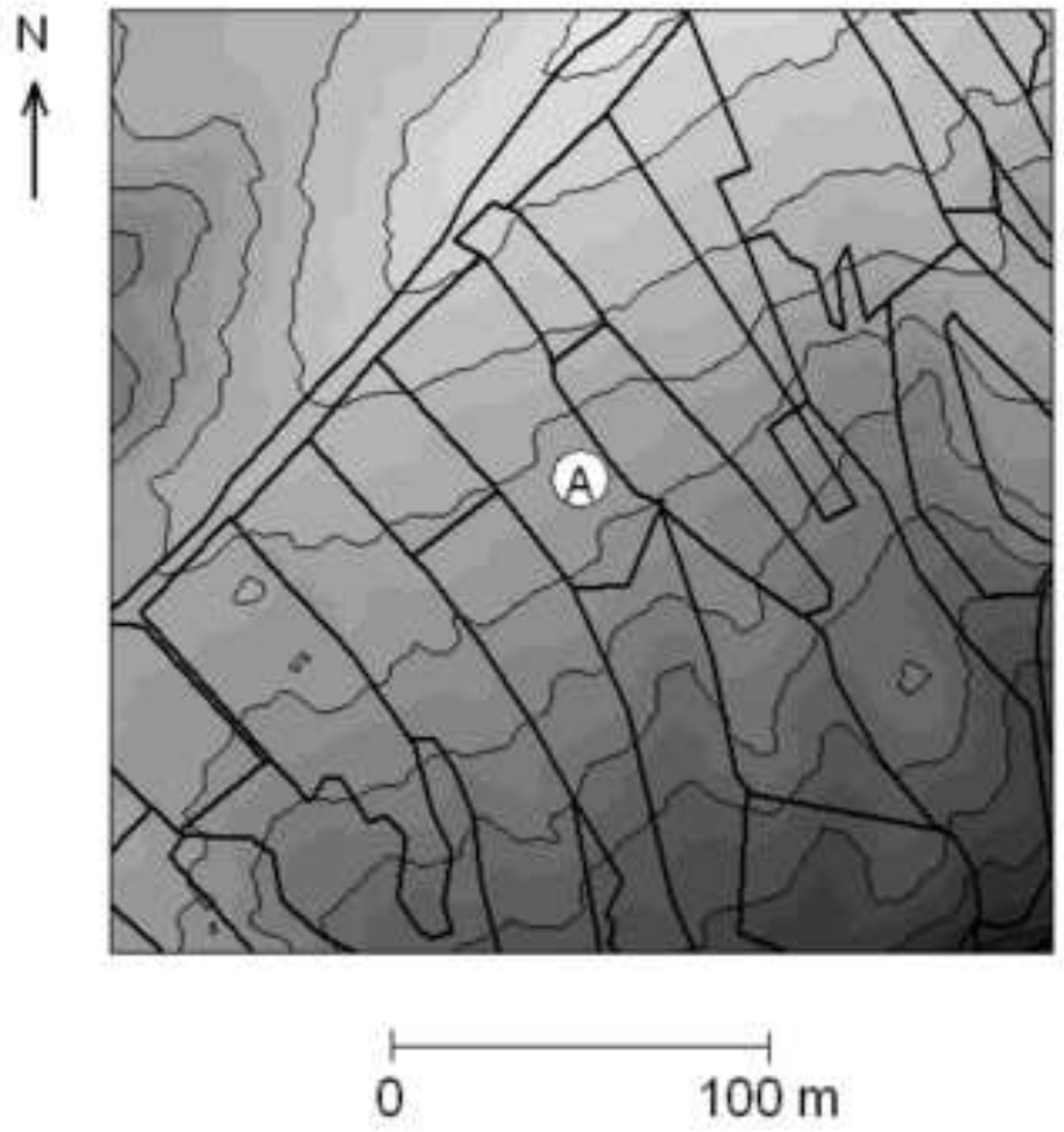
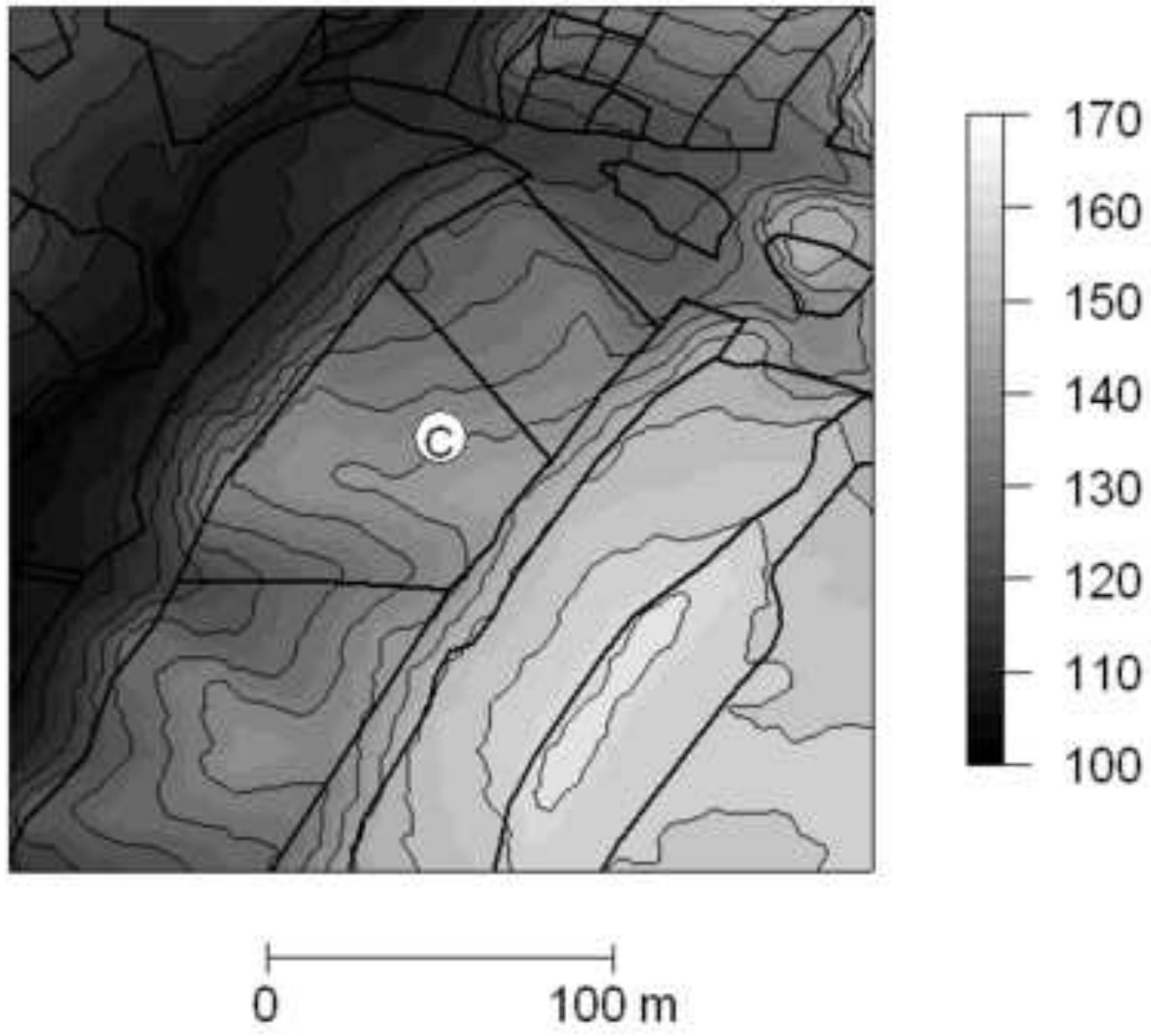

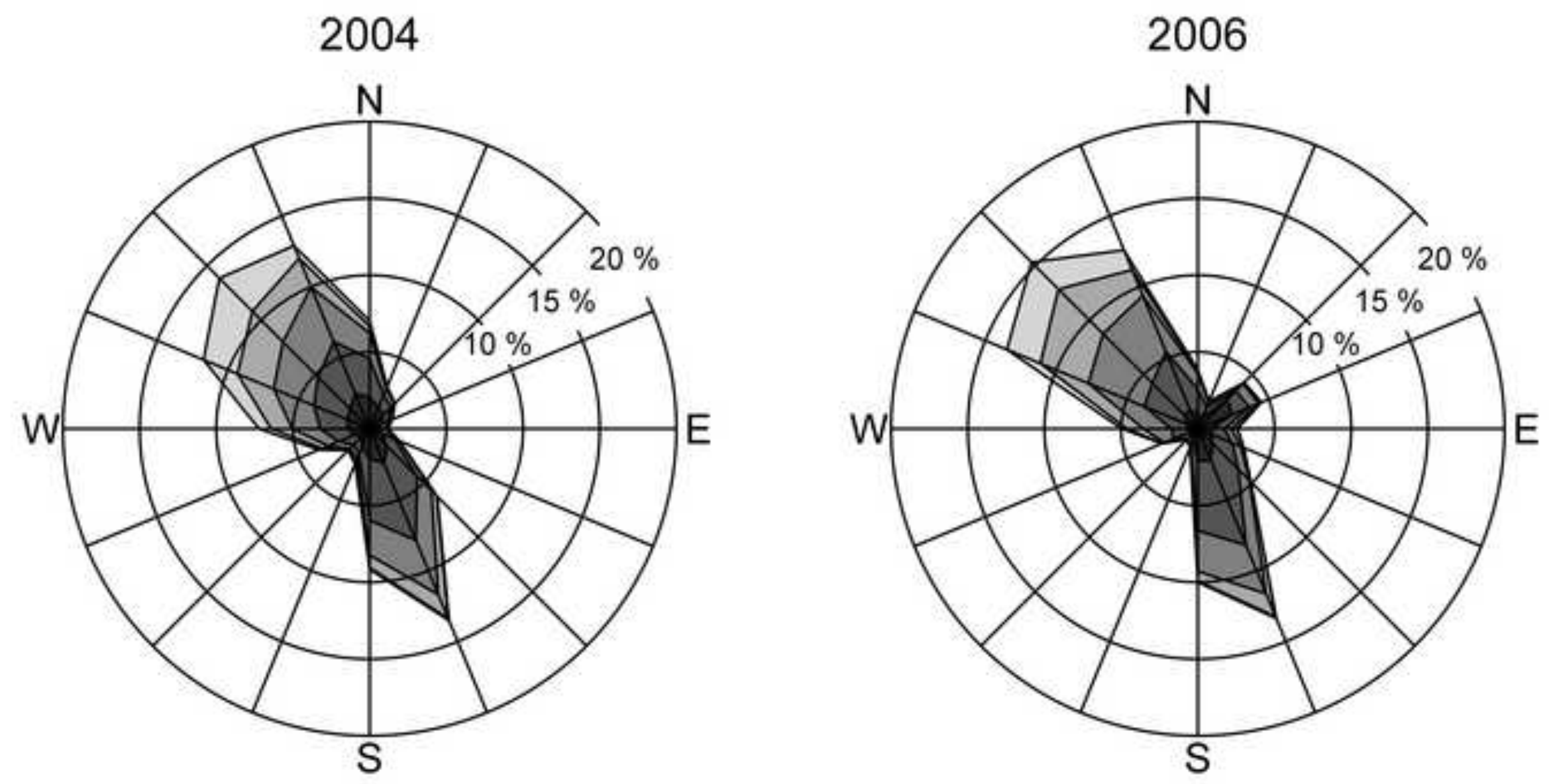

$\mathrm{m} / \mathrm{s}$

- 0-2 $\square$ 2-4 $\square$ 4-6 $\square$ 6-8 $\square>8$ 
length $(\mathrm{m})$

width (m)
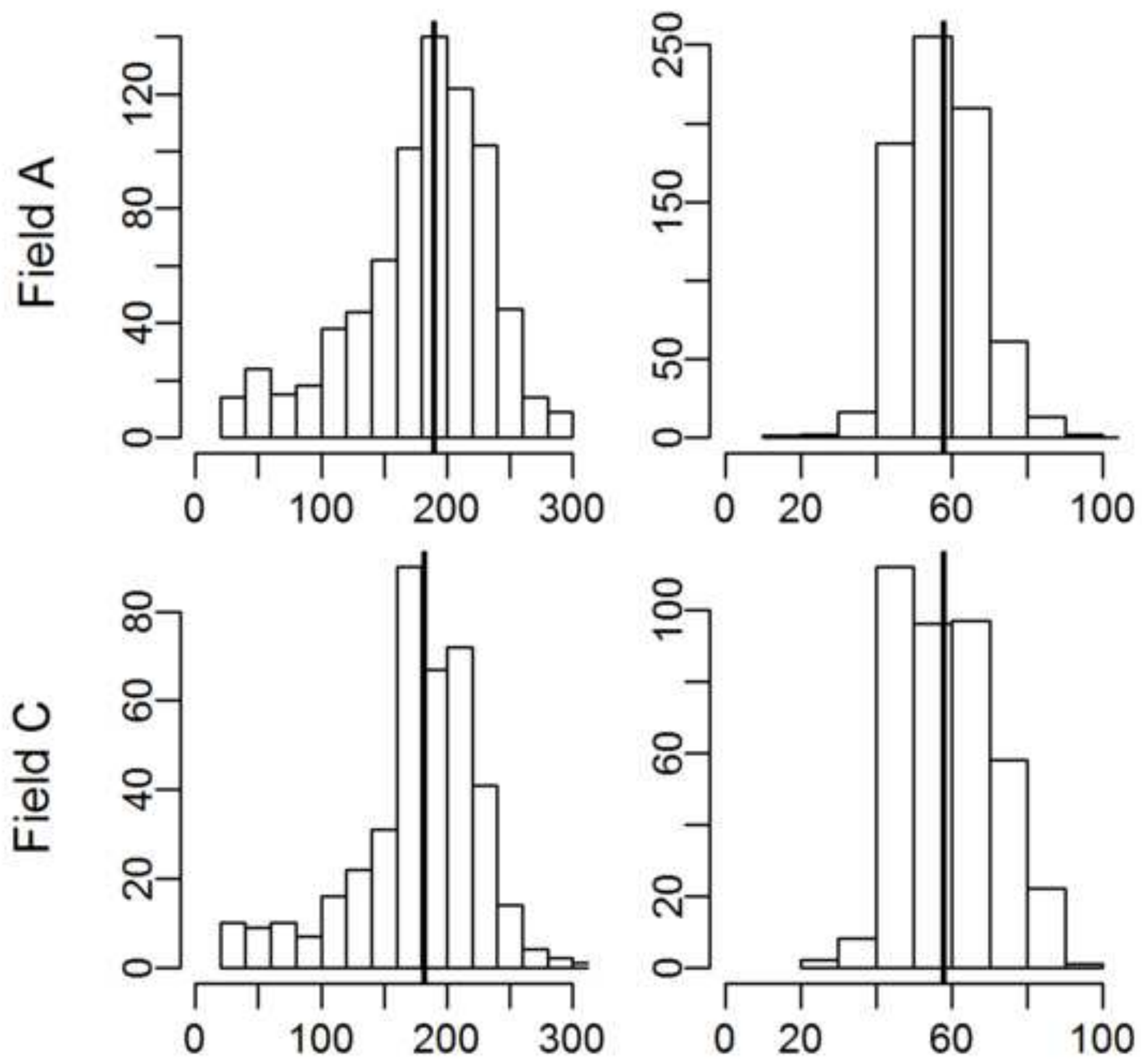
South winds
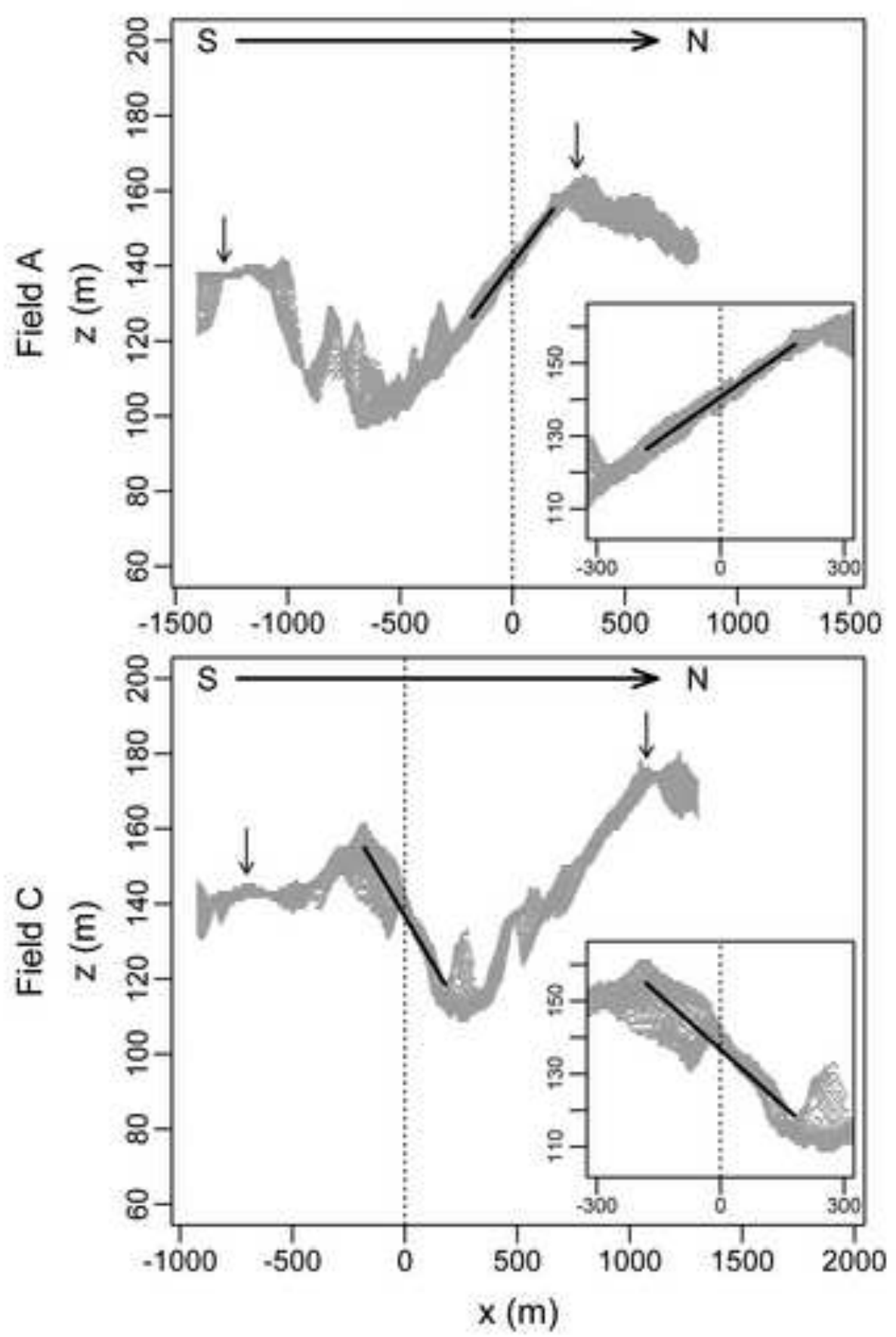

Northwest winds
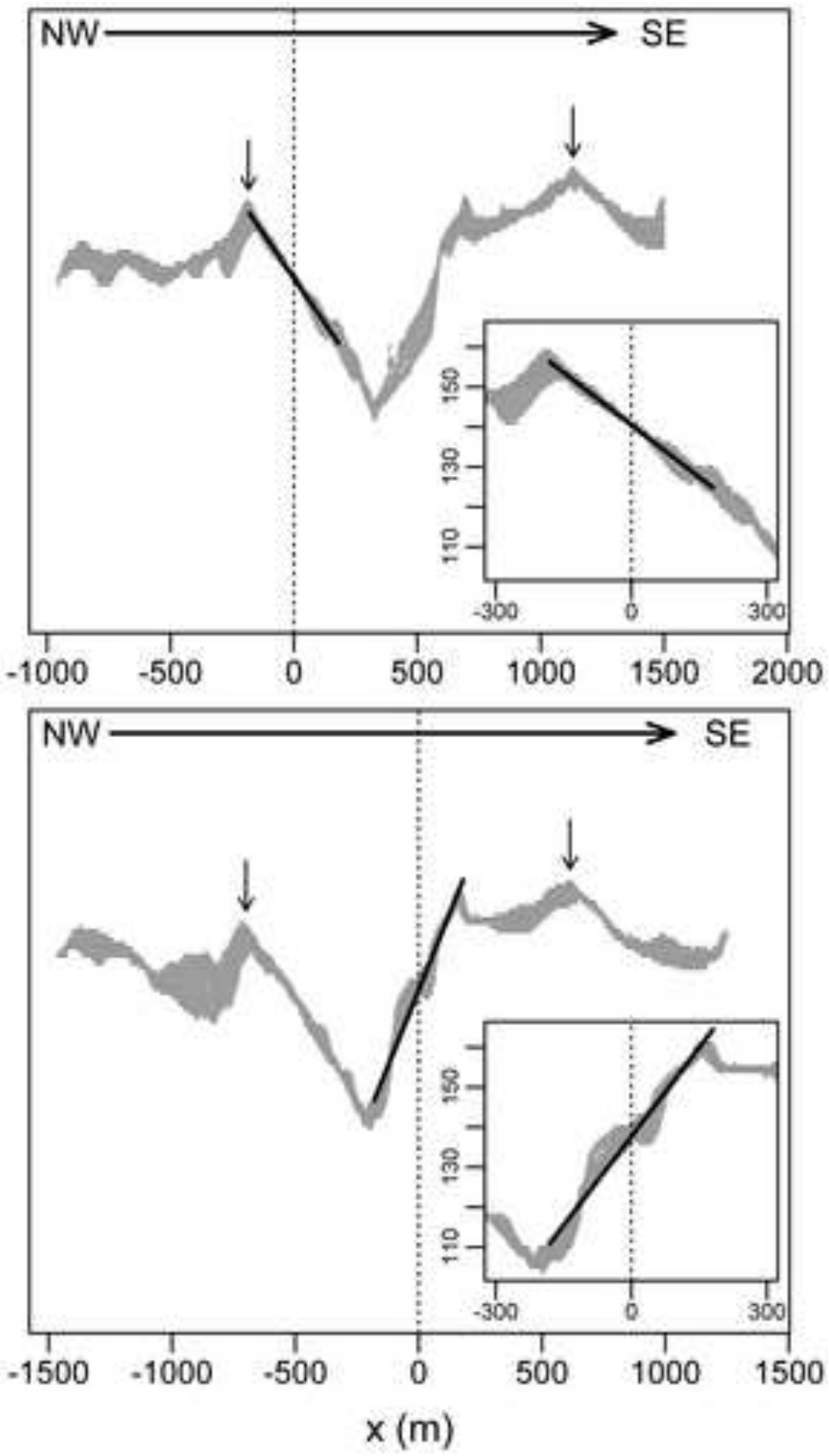


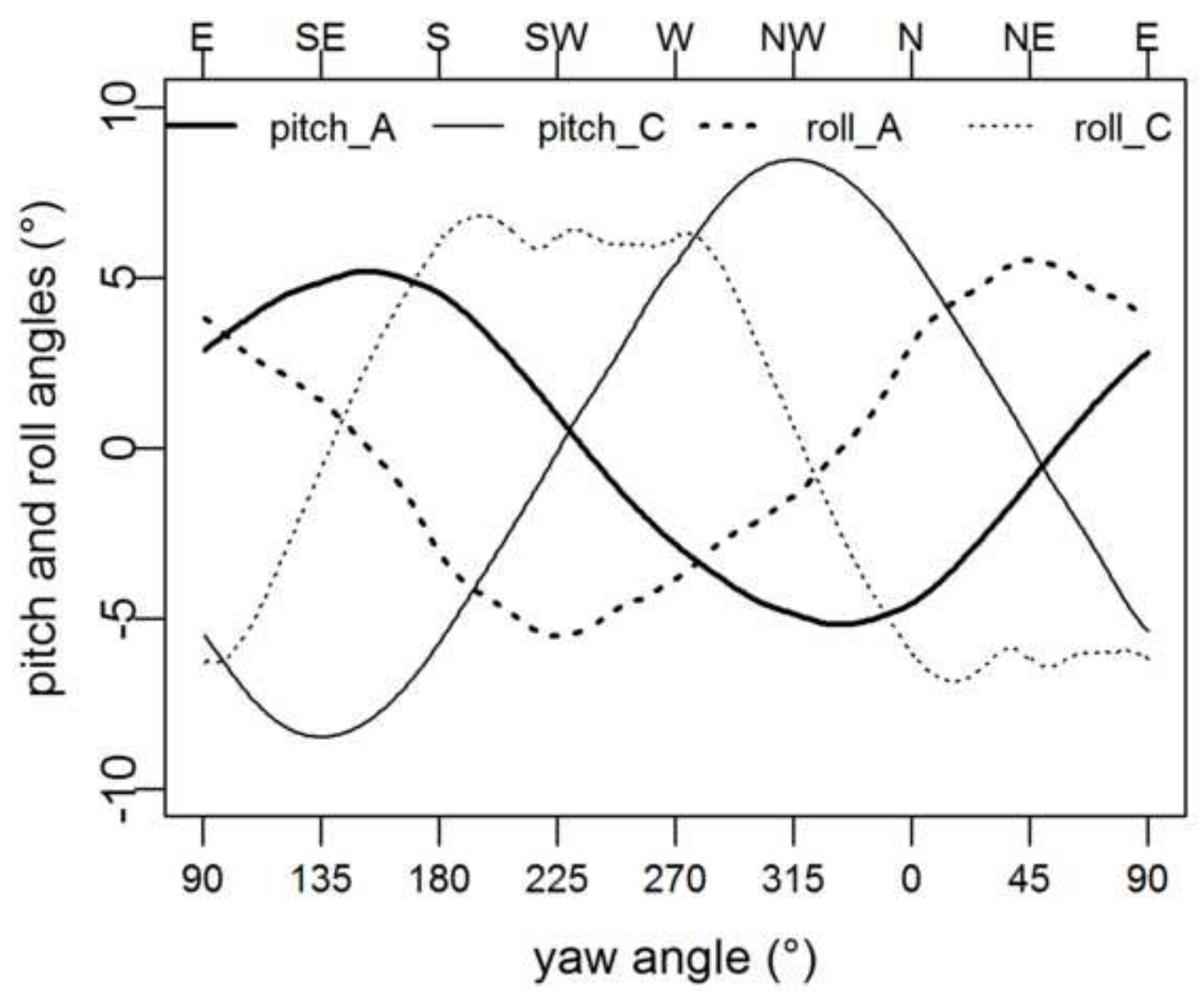



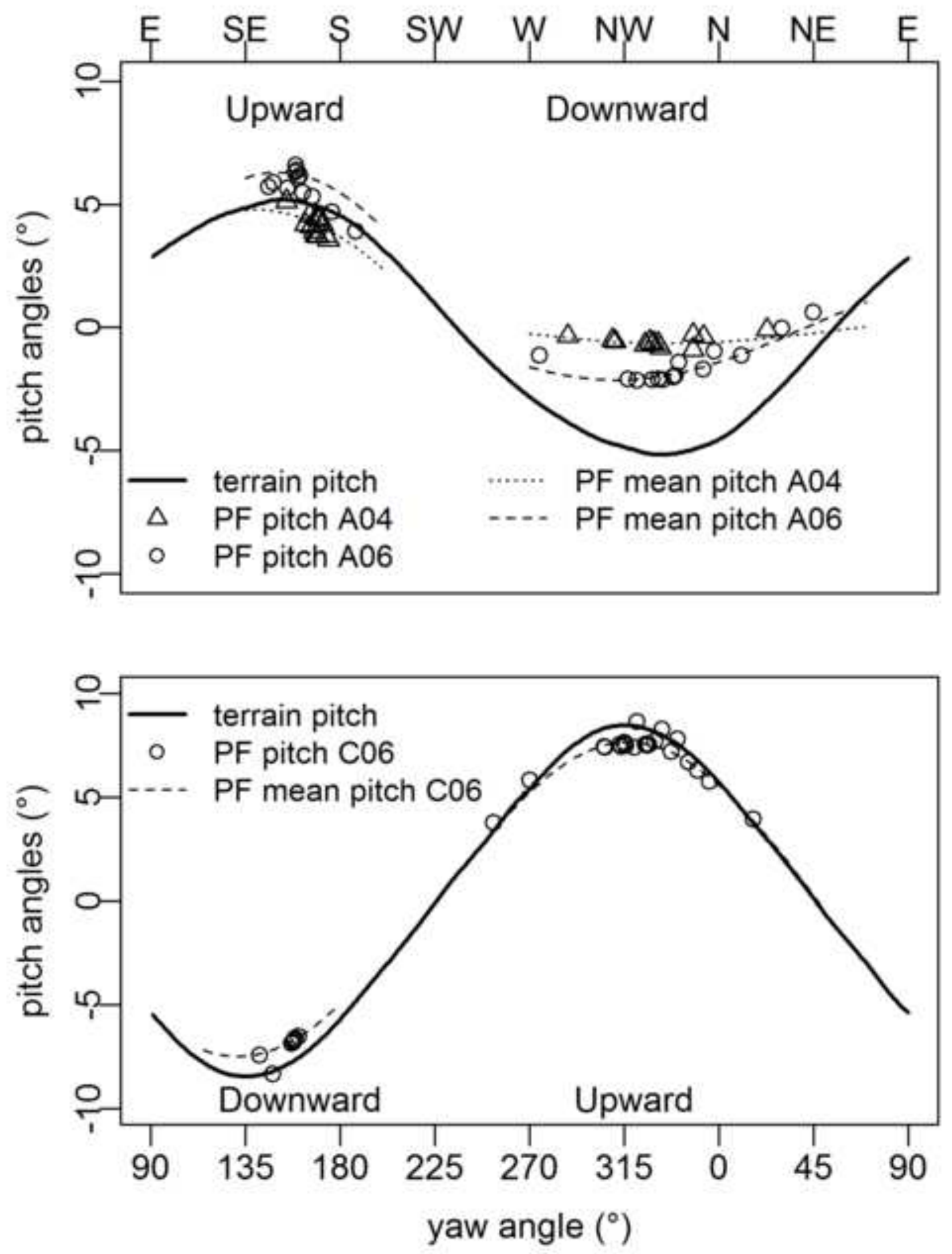

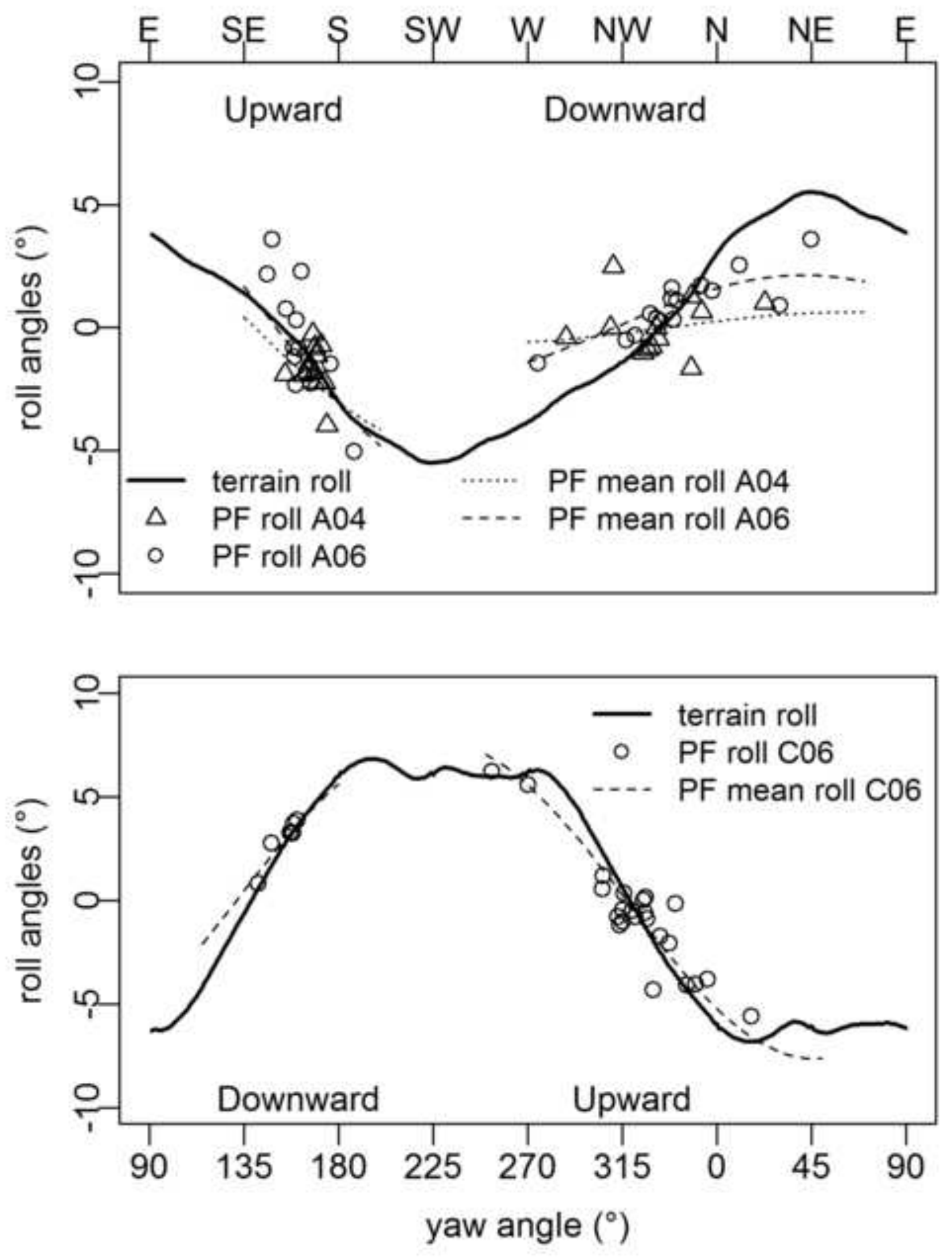

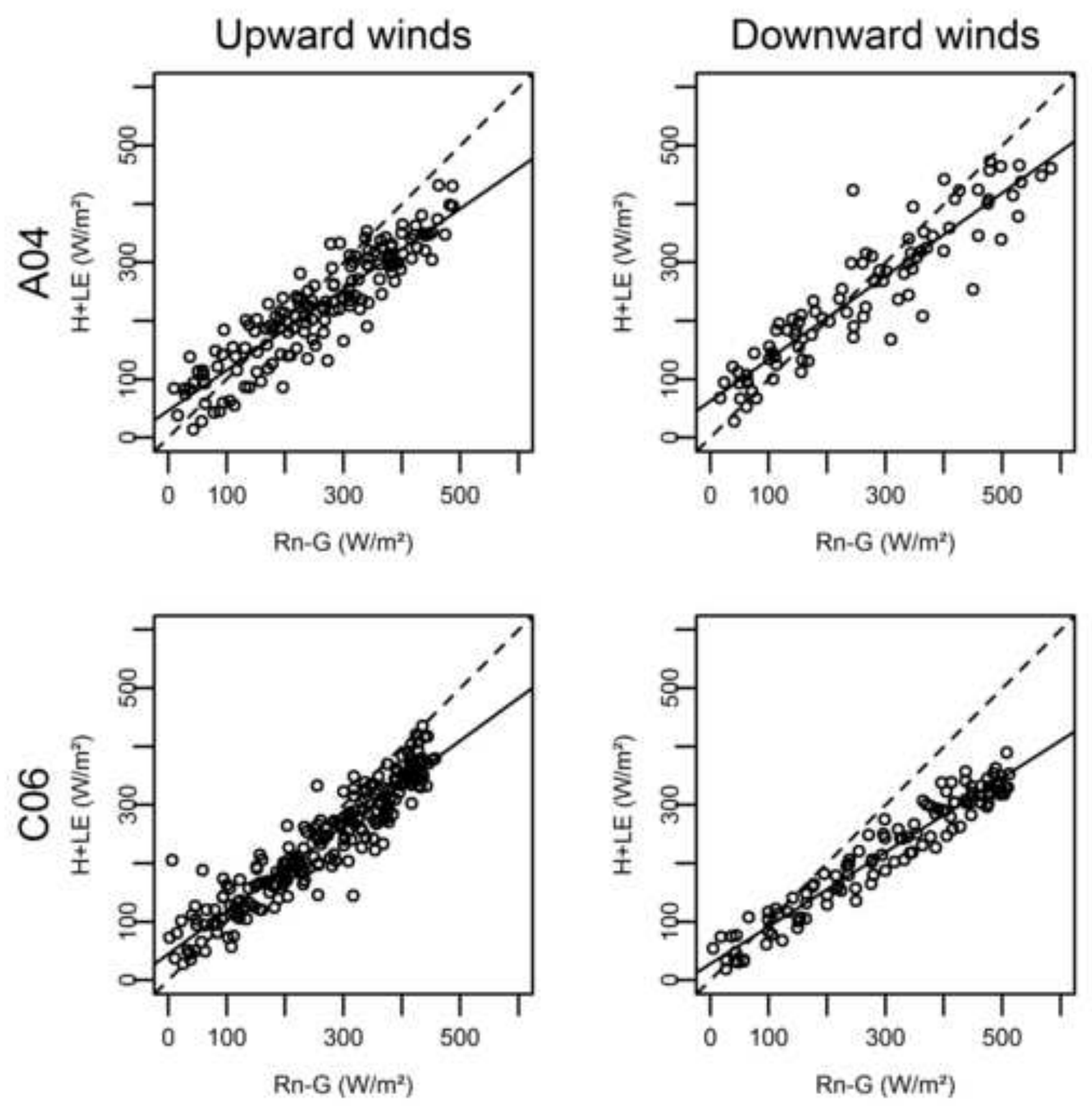